Federal Reserve Bank of Dallas

Globalization and Monetary Policy Institute

Working Paper No. 144

http://www.dallasfed.org/assets/documents/institute/wpapers/2013/0144.pdf

\title{
A Bargaining Theory of Trade Invoicing and Pricing*
}

\author{
Linda Goldberg \\ Federal Reserve Bank of New York \\ NBER \\ Cédric Tille \\ Geneva GIIDS \\ CEPR
}

April 2013

\begin{abstract}
We develop a theoretical model of international trade pricing in which individual exporters and importers bargain over the transaction price and exposure to exchange rate fluctuations. We find that the choice of price and invoicing currency reflects the full market structure, including the extent of fragmentation and the degree of heterogeneity across importers and across exporters. Our study shows that a party has a higher effective bargaining weight when it is large or more risk tolerant. A higher effective bargaining weight of importers relative to exporters in turn translates into lower import prices and greater exchange rate pass-through into import prices. We show the range of price and invoicing outcomes that arise under alternative market structures. Such structures matter not only for the outcome of specific exporter-importer transactions, but also for aggregate variables such as the average price, the average choice of invoicing currency, and the correlation between invoicing currency and the size of trade transactions.
\end{abstract}

JEL codes: F30, F40

\footnotetext{
* Linda Goldberg, Federal Reserve Bank of New York, 33 Liberty Street, New York, NY 10045. 212-7202836. linda.goldberg@ny.frb.org. Cédric Tille, Department of Economics, Graduate Institute for International and Development Studies, Pavillon Rigot, Avenue de la Paix 11A, 1202 Genève, Switzerland. 41-22-908-59-28. cedric.tille@graduateinstitute.ch. We thank Charles-Henry Weymuller and seminar participants at the Federal Reserve Bank of New York, the HEID-EPFL-UNIL Sinergia workshop, the Bank of Italy, the National Bank of Serbia, the University of Reading, the University of Navarra, and the University of Basel for valuable comments. Cédric Tille gratefully acknowledges financial support from the Swiss National Science Foundation Sinergia program, and the National Centre of Competence in Research "Financial Valuation and Risk Management" (NCCR FINRISK), and the Swiss Finance Institute. The views in this paper are those of the authors and do not necessarily reflect the views of the Federal Reserve Bank of Dallas, the Federal Reserve Bank of New York or the Federal Reserve System.
} 


\section{Introduction}

What determines the currency used in the invoicing of international trade? This question is the subject of an extensive theoretical and empirical research agenda in international economics as it plays a central role in determining whom among exporters or importers bear the cost of exchange rate fluctuations, and whether these fluctuations affect trade quantities. The existing theoretical literature has identified a host of determinants of the choice of invoicing currency in international trade, including a "coalescing" motive for exporters to keep their prices close to their competitors', a "hedging" motive to movements in marginal revenue in line with marginal cost fluctuations, transaction costs in foreign exchange markets, and the role of macroeconomic conditions that favor the use of low volatility currencies. ${ }^{1}$

A limit of existing contributions is the assumption that the choice of the invoicing currency rests solely with the exporter, who takes into account the downward sloping demand of importers. This assumption of unilateral decision-making is however at odds with growing evidence that the invoicing choice reflects a bargaining between exporters and importers (see Friberg and Wilander 2008 and Ito et al. 2012).

This paper addresses this limit by developing a richer model of the interaction between exporters and importers. We develop a simple model of bargaining between individual exporters and importers, with each taking into account the outside option of her counterpart. The negotiating covers both the allocation of exchange rate risk through the choice of invoicing currency and the price level in that currency. ${ }^{2}$

\footnotetext{
${ }^{1}$ Aggregate macroeconomic conditions impoly choosing a currency with low transaction costs (Devereux and Shi 2005 and Portes and Rey 2001), low macroeconomic volatility (Devereux, Engel, and Storgaard 2004), and hedging benefits which take into account the use of imported inputs (Novy 2006). The role of exporter market share is emphasized (Bacchetta and van Wincoop 2005, and Auer and Schoenle 2012), as is coalescing across his competitors contingent on demand elasticities and production curvature (Goldberg and Tille 2008). Endogenous currency choice also arises in a framework of uncertain timing of future price resets (Gopinath, Itskhoki, and Rigobon 2010).

${ }^{2}$ Recent works that focus on strategic interactions across competing exporting firms, but
} 
In our model a range of exporters produce goods at a cost and sell them to a range of importers, who in turn resell these goods in their domestic market. Each exporter - importer pair bargains over the two aspects of the contract: a preset contract price that prevails in the absence of exchange rate movements between the time of contracting and the time of the actual transaction, and the allocation of exposure to exchange rate movements around that preset price (i.e. the invoicing currency), which maps directly to rates of ex-post exchange rate pass through. We consider a standard Nash bargaining that maximizes a joint surplus which is a weighted average of the exporter's and importer's surpluses, with the weights referred to as the formal bargaining weights of the parties. ${ }^{3}$ As all exporters transact with all importers in equilibrium, the surplus that an exporter gets from a successful match with a specific importer is the utility of the profits from transacting with all importers minus the utility of the profits from transacting with all importers except the specific importer in the bargaining. The surplus for an importer is defined similarly.

Our analysis includes three key ingredients. First, exporters and importers have a concave valuation of payoffs. Failing to reach an agreement with a large counterpart then has a larger impact on the marginal valuation of payoffs than failing to reach one with a small counterpart. Second, uncertainty plays a central role as the bargaining takes place before exchange rate fluctuations are realized. Third, we allow for heterogeneity of exporters and importers, with heterogeneity taking the form of numbers of counterparts or relative sizes of counterparts. To our knowledge this paper is the first analysis of the joint determination of pricing and invoicing through a bargaining in the presence of uncertainty and heterogenous valuations of payoffs.

The key relations in our analysis are the first-order conditions that maximize the joint surplus of a specific exporter - importer pair with respect to the preset price and the exchange rate exposure. Two conditions are derived for each exporter - importer pair. As they are highly non-linear, we first solve for the optimal prices in a steady-state with no uncertainty. We then solve for the exchange rate exposure by relying on a quadratic approximation around the steady-state, such an approximation being needed to capture the second moments that drive the choice without a focus on the importer competition or bargaining, include deBlas and Russ (2012) and Garetto (2012).

${ }^{3}$ The weights are the same across all exporter - importer pairs. 
of exposure. In general the preset price and exposure choice for a specific exporter - importer pair depends on the choices for other pairs, as these affect the marginal value of payoffs for the parties. As this leads to a highly complex solution, we consider two specific cases to highlight the key results. The first case focuses on the degree of fragmentation among exporters and among importers, defined as the number of identical agents in each group. The second case emphasizes intra-group heterogeneity, defined as the relative size of agents within each group, setting the number of agents per group to two.

The analysis leads to a number of novel results. First, the outcomes of the bargaining reflects the effective bargaining weights of the counterparts that differ from the formal weights in the joint surplus. A counterpart gets a higher effective bargaining weight when she is big and when the concavity of her valuation of payoffs is limited. The size of a counterpart is measured by the share of her counterpart's payoffs that she accounts for in equilibrium. ${ }^{4}$ Second, the preset price is tilted in favor of the counterpart with the highest effective bargaining weight. This party then gets most of the surplus from the match, but also has a lower marginal value of payoffs relative to the other party due to the concavity of valuation of payoffs. Third, the counterpart with the highest effective bargaining weight bears more of the exchange rate risk. This result is both interesting and intuitive. This counterpart has a relatively low marginal value of payoffs, which implies that expost movements have a relatively limited impact on marginal utility. These results also underscore the importance of considering a bargaining process that covers all aspects of the price contract, and not just the exchange rate exposure. Fourth, in the presence of intra-group heterogeneity, the relative sizes of agents within each group affect the outcome not only for specific pairs but also in aggregate terms. Specifically, a situation of high exporter heterogeneity (with one exporter dominating the market) is characterized by a higher average level of preset prices across pairs, a higher average exposure of exporters to exchange rate movements (more importer currency pricing), and a positive correlation between the value of transactions and the exchange rate exposure of exporters.

In addition to its contribution to our understanding of the determinants of international trade invoicing and price-setting, this paper provides a methodological contribution by solving a bargaining model under uncertainty where the marginal

\footnotetext{
${ }^{4}$ For instance the exporter's size in a specific exporter - importer pair is the share of the importer's profits that stems from buying and selling the goods produced by the exporter.
} 
valuations of payoffs differs across the parties. As outlined in the discussion of the related literature, existing contributions consider some of the aspects of our framework (such as uncertainty or different valuations of payoffs), but our analysis is to our knowledge the first that encompasses the combined features.

The paper is organized as follows. We review the related literature on pricing and invoicing currency choice, as well as on bargaining games, in Section 2. Section 3 presents the main features of the model, and Section 4 provides the solution method. Sections 5 derives the outcomes for preset prices and exchange rate exposure in specific examples, focusing first on fragmentation and then on intra-group heterogeneity among exporters and importers. Section 6 concludes. Throughout the paper we focus on an intuitive presentation of the main points. The key technical aspects are presented in the Appendix and the detailed derivations are in a Technical Appendix available on request.

\section{Related literature}

Our work fits in the literature on invoicing choice and price adjustments in international economics, providing additional theoretical underpinnings on the roles of firm and industry-level heterogeneity that are found to be important in empirical studies. Goldberg and Tille (2011) consider a highly disaggregated data set of Canadian imports and find a robust link between invoice currency choice, the size of individual transactions, and heterogeneity of transacting agents. Berman, Martin, and Mayer (2012) analyze rich data for French firms and find that high performance firms have markups that respond more to exchange rate movements, and are more willing to engage in producer currency pricing. ${ }^{5}$ Gopinath, Itskhoki, and Rigobon (2010) show that invoice currency choice is closely related to the pass-through of cost fluctuations into final prices in the United States, with much higher pass-through for import prices set in currencies other than the dollar. Price rigidities do not fully explain this phenomenon. ${ }^{6}$

\footnotetext{
${ }^{5}$ For these firms, quantities of high performance firms also respond by less to exchange rate changes. Sectoral heterogeneity in pricing also varies according to types of goods, with more local currency pricing on consumer goods than intermediate goods, and more for sectors with higher distribution costs.

${ }^{6}$ As our model assumes that prices are fully preset, up to the exchange rate exposure, we cannot consider the relation between the choice of invoicing and the response of prices to cost
} 
Our paper also relates to the industrial organization literature on bargaining games between suppliers and retailers. To our knowledge, our paper is the first contribution introducing bargaining between buyers (exporters) and sellers (importers) in the context of concave valuation of payoffs in an uncertain environment. The nearest contributions include DeGraba (2005), who presents a model where the valuation of goods varies across buyers. Sellers make price offers that the buyers can accept or refuse. As the seller cannot observe the true valuation of her counterpart, she has an incentive to offer better conditions to larger buyers as loosing a large customer is more costly than loosing a larger one. While the DeGraba model includes uncertainty, it does so in the form of idiosyncratic valuations and thus abstracts from the role of aggregate risk such as that arising from exchange rate movements. The role of curvature in valuation, which we assume, has a precedent in the framework of Normann et al. (2003) wherein a seller with increasing marginal costs of production makes take it or leave it offers to buyers. The seller offers a lower price to large buyers as large sales take place at a point on the curve schedule where the marginal cost his low. The setting however does not include uncertainty.

A number of other papers provide theoretical precedent for our treatment of counterpart heterogeneity and fragmentation through their focus on merger incentives in multi-agents games. Inderst and Wey (2003) develop a framework where prices are set between two retailers and two producers, but assume that all agents share the same marginal valuation of resources in contrast to our setting of heterogenous concave valuations. ${ }^{7}$ Horn and Wolinsky (1988) analyze a setting with two buyers and two sellers where the marginal valuation of the price can differ between buyers and sellers, and focus on the incentives of agents to merge and form a monopoly, showing that this is not necessarily an optimal choice because of the impact on bargaining power. The model, however, assumes that each buyer only purchases from one seller, and thus abstracts from the ability of buyers to play one seller against another to gain a better bargaining position. Dowbson and Waterson (1997) consider a larger number of identical buyers, but abstract from uncertainty

fluctuations. Our assumption is motivated by our focus on invoicing in a novel pricing framework, and extending it to include price adjustment is left for future work. The relevance of market structure for invoicing is likely to extend to price adjustment as well.

${ }^{7}$ Similarly, Chipty and Snyder (1999) focus on the incentives for mergers among buyers and sellers assuming that they share the same marginal valuation of the price. 
and heterogeneity in payoffs' valuation. Camera and Selcuk (2009) show how price heterogeneity can arise in a setting with homogenous buyers and homogenous sellers, but abstract from uncertainty. This follows from capacity constraints faced by sellers, while the heterogeneity in our model reflect different sizes of agents. Selcuk (2012) introduces risk averse differences between buyers and sellers. A seller faced with risk-averse buyers opts to set a fixed price so that buyers are not exposed to ex-post price risk. In his setting the price, the risk facing the buyer is due to limited sellers' inventories, instead of the macroeconomic risk that we consider. In addition, risk aversion is limited to one side of the market.

Overall, our setting differs from the existing theoretical contributions in the industrial organization literature in that we consider aggregate uncertainty, heterogenous marginal valuation of payoffs through concave valuations, and heterogeneity in terms of agents sizes.

\section{An exporter-importer bargaining model}

\subsection{Structure and payoffs}

Two types of agents are in the model: importers and exporters. There are $M$ importers indexed by $j$, and $X$ exporters indexed by $i$. Exporters sell goods to importers, who in turn resell these goods to customers in the destination country.

A specific importer $m$ buys $Q_{x m}$ units of goods from a specific exporter $x$ and resells these goods at a price $Z_{m}$ in her currency. Exporter $x$ has an average production cost denoted by $C_{x m}$ and denominated in her currency. Each importer can purchase goods from all exporters, and each exporter can sell goods to all importers. When transactions occur for all exporter-importer pairs (which is the case in equilibrium) the payoff of importer $m$ is a concave valuation of her expected profits:

$$
U_{m}=\frac{1}{1-\gamma_{M}} E\left(\sum_{i=1}^{X}\left(Z_{m}-P_{i m}^{m}\right) Q_{i m}\right)^{1-\gamma_{M}}
$$

where $E$ is the expectation operator, $\gamma_{M}$ captures the concavity of the importer's valuation of payoffs (and her risk aversion) that is common to all importers, and

$P_{i m}^{m}$ is the price charged by exporter $i$ to importer $m$, with the $m$ superscript denoting that this price is expressed in the importer's currency. The payoff of 
exporter $x$ is a concave valuation of her expected profits:

$$
U_{x}=\frac{1}{1-\gamma_{X}} E\left(\sum_{j=1}^{M}\left(P_{x j}^{x}-C_{x j}\right) Q_{x j}\right)^{1-\gamma_{X}}
$$

where $\gamma_{X}$ captures the concavity of the exporter's valuation of payoffs (common to all exporters), and $P_{x j}^{x}$ is the price charged by exporter $x$ to importer $j$, with the $x$ subscript denoting that it is expressed in the exporter's currency. The specifications (1)-(2) encompass two key features of the model, namely the presence of uncertainty with the valuation of payoffs being from an ex-ante perspective, and the concave valuation of payoffs reflected by the constant relative risk aversion paramaters, $\gamma_{M}$ and $\gamma_{X}$, that can differ between exporters and importers.

Our analysis focuses on the price charged by exporter $x$ to importer $m$. It entails two contractual components: a preset price component $P_{x m}^{f}$ that is fixed before shocks are realized, and the extent to which the price in the importer's currency moves with ex-post fluctuations in the exchange rate. Specifically, we denote the percentage of exchange rate movements that are transmitted to the importer's price by $1-\beta_{x m}$, where $\beta_{x m} \in(0,1)$. We interpret $\beta_{x m}$ as the extent of local currency pricing (LCP), which corresponds to the share of exchange rate movements that are absorbed by the exporter. If $\beta_{x m}=1$ the importer is shielded from exchange rate fluctuations, corresponding to full local currency pricing. If $\beta_{x m}=0$ the exporter's price is shielded from exchange rate fluctuations, a case referred to as producer currency pricing (PCP) in the literature. ${ }^{8}$ The exchange rate $S$ is defined as units of exporter's currency per unit of importer's currency, so that an increase corresponds to a depreciation of the exporter's currency. We assume, without loss of generality, that the log exchange rate $s$ is normally distributed around zero.

The price paid by the importer in her currency is:

$$
P_{x m}^{m}=P_{x m}^{f} S^{\beta_{x m}-1}
$$

Similarly the price received by the exporter in her currency is:

$$
P_{x m}^{x}=P_{x m}^{b} S=P_{x m}^{f} S^{\beta_{x m}}
$$

\footnotetext{
${ }^{8}$ Engel (2006) and Goldberg and Tille (2008) provide equivalence results on optimal exchange rate pass through and invoice currency choice when prices are sticky.
} 
The price between exporter $x$ and importer $m$ is determined through bilateral bargaining. A key element is the surplus that each counterpart gains from a successful match (defined as a negotiation that leads the pair $x m$ to undertake a transaction). In equilibrium there are transactions between all importer-exporter pairs, as all transactions generate some positive surplus making both exporter and importer better off by transacting. The surplus of the importer (exporter) specifically generated by the $x m$ transaction is the value of the payoff for the importer (exporter) from conducting transactions with all counterparts, minus the payoff she would get from conducting transactions with all counterparts except $x$ $(m) \cdot{ }^{9}$

Specifically, the expected surplus that importer $m$ derives from its negotiation with exporter $x$ is:

$$
\begin{aligned}
\Theta_{x m}^{m}= & \frac{1}{1-\gamma_{M}} E\left(\sum_{i=1}^{X}\left(Z_{m}-P_{i m}^{f} S^{\beta_{x m}-1}\right) Q_{i m}\right)^{1-\gamma_{M}} \\
& -\frac{1}{1-\gamma_{M}} E\left(\begin{array}{c}
\sum_{i=1}^{X}\left(Z_{m}-P_{i m}^{f} S^{\beta_{x m}-1}\right) Q_{i m} \\
-\left(Z_{m}-P_{x m}^{f} S^{\beta_{x m}}\right) Q_{x m}
\end{array}\right)^{1-\gamma_{M}}
\end{aligned}
$$

Similarly the surplus for $x$ from its negotiation with importer $m$ is:

$$
\begin{aligned}
\Theta_{x b}^{x}= & \frac{1}{1-\gamma_{X}} E\left(\sum_{j=1}^{M}\left(P_{x j}^{f} S^{\beta_{x j}}-C_{x j}\right) Q_{x j}\right)^{1-\gamma_{X}} \\
& -\frac{1}{1-\gamma_{X}} E\left(\begin{array}{c}
\sum_{j=1}^{M}\left(P_{x j}^{f} S^{\beta_{x j}}-C_{x j}\right) Q_{x j} \\
-\left(P_{x m}^{f} S^{\beta_{x m}}-C_{x m}\right) Q_{x m}
\end{array}\right)^{1-\gamma_{X}}
\end{aligned}
$$

We allow for the quantity $Q_{x m}$ to be price sensitive. Specifically, the demand by $m$ for goods produced by $x$ is inversely related to the ratio between the price $P_{x m}^{m}$ charged by $x$ to $m$, and a reference price denoted by $R_{x m}^{m}$ which reflects the prices that $m$ gets from other competing exporters. We consider a constant price elasticity of demand $\rho$. The reference price $R_{x m}^{m}$ is of a form similar to the price $P_{x m}^{m}$, and consists of a fixed component $R_{x m}^{m, f}$ and a component that is sensitive to the exchange rate: $R_{x m}^{m}=R_{x m}^{m, f} S^{\eta_{x m}-1}$, where $\eta_{x m}$ is the extent to which the

\footnotetext{
${ }^{9}$ The structure is similar to Chipty and Snyder (1999) where an individual buyer negotiates with the seller assuming that the seller will trade with all other buyers, so that each buyer views himself as being the marginal buyer.
} 
reference price is stable in the importer's currency. A more detailed presentation of the reference price is provided in the numerical examples of sections 4 and 5 . The quantity sold from $x$ to $m$ is then written as:

$$
Q_{x m}=Q_{x m}^{s e t}\left[\frac{P_{x m}^{f}}{R_{x m}^{m, f}} S^{\left(\beta_{x m}-\eta_{x m}\right)}\right]^{-\rho}
$$

where $Q_{x m}^{s e t}$ is the exogenous component of demand, which is not affected by the outcome of the price and invoice currency bargaining.

The quantity $Q_{x m}$ is produced according to a decreasing returns to scale technology which uses an input $L_{x m}$. We assume that the technology, and hence the average and marginal costs, apply separately to each $x m$ pair. ${ }^{10}$ Specifically the technology is $Q_{x m}=A_{x m}\left(L_{x m}\right)^{\lambda}$ where $A_{x m}$ is a constant parameter and $\lambda \leq 1$. For simplicity, we assume that the production by exporter $x$ of the goods she sells to $m$ is not affected by the quantities she sells to other importers, and so are the average cost $C_{x m}$ and the marginal cost $M C_{x m}=\lambda^{-1} C_{x m} \cdot{ }^{11}$ We allow for the unit cost of the input to be affected by the exchange rate, for example due to the use of imported inputs in production, and denote the unit cost by $W_{x} S^{\zeta_{x}}$ where $W_{x}$ is exogenous and $\zeta_{x}$ is the elasticity of the cost with respect to the exchange rate. Under this specification the marginal cost of production is:

$$
M C_{x m}=\frac{1}{\lambda} W_{x} S^{\zeta_{x}}\left(A_{x m}\right)^{-\frac{1}{\lambda}}\left[Q_{x m}^{s e t}\left[\frac{P_{x m}^{f}}{R_{x m}^{m, f}} S^{\left(\beta_{x m}-\eta_{x m}\right)}\right]^{-\rho}\right]^{\frac{1-\lambda}{\lambda}}
$$

We consider a partial equilibrium setting in order to focus on the interaction between the respective exporters and importers. In particular, we take several variables to be exogenous, such as the exchange rate $S$, the final price $Z_{m}$, the wage $W_{x}$, the reference price $R_{x m}^{m}$, and the demand shifter $Q_{x m}^{s e t}$. We consider that these variables are stochastic, and possibly correlated.

\subsection{Determination of price}

The two components of the contract negotiated between $x$ and $m$, namely the preset contract price $p_{x m}^{f}$ and the extent of invoicing in the importer's currency

\footnotetext{
${ }^{10}$ Accordingly, there is no spillover of the outcome between a specific importer-exporter pair and the costs for another transacting pair.

${ }^{11}$ This can be interpreted as $x$ operating a plant producing only for sales to $m$. If instead we assume that the plant produces for all of $x$ 's customers, sales to importers other than $m$ would affect the marginal cost of selling to $m$.
} 
$\beta_{x m}$, are set to maximize a combination of the exporter's and importer's surpluses (3) and (4). We consider a Nash bargaining where the combination is a geometric averages of the surpluses, with weights representing the formal bargaining weights of the parties. This approach is standard in the bargaining literature, as in Chipty and Snyder (1999), Dowbson and Waterson (1997), and Horn and Wolinsky (1988). Specifically we define the joint surplus of a match between $x$ and $m$ as:

$$
\Theta_{x m}^{j o i n t}=\left[\Theta_{x m}^{m}\right]^{\delta}\left[\Theta_{x m}^{x}\right]^{1-\delta}
$$

where $\delta$ captures the formal weight of the importer in the bargaining, and is assumed to be the same for all $x m$ pairs. It reflects the role that the importer plays in determining the price and invoicing. The cases of $\delta=0$ is the situation where the exporter makes the decision unilaterally to maximize her surplus given her knowledge of all the relevant parameters of demand. Similarly, the importer is the sole decider when $\delta=1$. Each party has an equal say when $\delta=0.5$. The assumption that the two parties have identical weights (i.e $\delta=0.5$ ) is standard in the literature (Chipty and Snyder 1999, Dowbson and Waterson 1997, and Horn and Wolinsky 1988)

The preset contract price $P_{x m}^{f}$ and extent of LCP $\beta_{x m}$ are chosen to maximize (7) leading to the two following conditions:

$$
\begin{aligned}
0 & =\delta \frac{\partial \Theta_{x m}^{m}}{\partial P_{x m}^{f}} \Theta_{x m}^{x}+(1-\delta) \frac{\partial \Theta_{x m}^{x}}{\partial P_{x m}^{f}} \Theta_{x m}^{m} \\
0 & =\delta \frac{\partial \Theta_{x m}^{m}}{\partial \beta_{x m}} \Theta_{x m}^{x}+(1-\delta) \frac{\partial \Theta_{x m}^{x}}{\partial \beta_{x m}} \Theta_{x m}^{m}
\end{aligned}
$$

The exact expression of the various derivatives in (8) and (9) are complex and given in the appendix. ${ }^{12}$

\footnotetext{
${ }^{12}$ Our framework differs significantly from, and complements, that of Gopinath, Itskhoki and Rigobon (2010). Our model focuses on the interaction between heterogeneous exporters and importers. We abstract from dynamics by considering an ex-ante stage with the negotiation over the terms of a contract that yields the relevant decisions on ex ante pricing and allocation of exchange rate risk, and an ex-post stage where shocks are realized and exchange rate movements are transmitted to prices according to the agreed exposure. Unlike the multiperiod framework of Gopinath, Itskhoki and Rigobon (2010), we do not consider staggered and uncertain timing of pricing adjustments, and thus cannot discuss the connection between exchange rate exposure and pass-through at the time when prices are adjusted, which is central in their analysis.
} 


\section{Solution method}

\subsection{Steady state}

The first-order conditions (8) and (9) are non-linear functions of the pricing components not only between $x$ and $m$, but also between $x$ and the other importers, as well as between $m$ and the other exporters. This reflects the fact that the surpluses (3)-(4) are affected by all of the exporter-importer transactions.

As there is no closed-form solution of the system (8) and (9), we consider approximations around a steady state where there is no uncertainty. We denote steady-state variables with an upper bar. Without loss of generality we assume that the exchange rate is equal to unity: $\bar{S}=1$. The price in any currency then corresponds to its preset component $\left(\bar{P}_{x m}^{m}=\bar{P}_{x m}^{x}=\bar{P}_{x m}^{f}\right)$ which we denote by $\bar{P}_{x m}$ for brevity.

A convenient way to capture the relevance of importer $m$ for exporter $x$ is to compute the share of $x$ 's total profits that are accounted for by sales to $m$ :

$$
\Pi_{x m}^{m}=\frac{\left(\bar{P}_{x m}-\bar{C}_{x m}\right) \bar{Q}_{x m}}{\sum_{j=1}^{M}\left(\bar{P}_{x j}-\bar{C}_{x j}\right) \bar{Q}_{x j}}
$$

with a high value of $\Pi_{x m}^{m}$ indicating that the importer $m$ is large from the point of view of the exporter $x$. Similarly the relevance of exporter $x$ for importer $m$ is the share of $m$ 's profits that come from sales of goods provided by $x$ :

$$
\Pi_{x m}^{x}=\frac{\left(\bar{Z}_{m}-\bar{P}_{x m}\right) \bar{Q}_{x m}}{\sum_{i=1}^{X}\left(\bar{Z}_{m}-\bar{P}_{i m}\right) \bar{Q}_{i m}}
$$

with a high value of $\Pi_{x m}^{x}$ indicating that the exporter $x$ is large from the point of view of the importer $m$.

The invoicing share $\beta_{x m}$ does not enter the steady-state solution. ${ }^{13}$ Intuitively, it is not a meaningful dimension of the model in the absence of exchange rate fluctuations. ${ }^{14}$ We therefore focus on the steady state value of (8) which is:

$$
\begin{aligned}
& \tilde{\delta}_{x m}\left(\bar{P}_{x m}-\frac{\rho}{\rho-1} \bar{Z}_{m}\right)\left(\bar{P}_{x m}-\bar{C}_{x m}\right) \\
= & \left(1-\tilde{\delta}_{x m}\right)\left(\bar{P}_{x m}-\frac{\rho}{\rho-1} \overline{M C}_{x m}\right)\left(\bar{Z}_{m}-\bar{P}_{x m}\right)
\end{aligned}
$$

\footnotetext{
${ }^{13}$ Specifically, both sides of (9) are zero when evaluated at the steady state.

${ }^{14} \mathrm{~A}$ parallel intuition arises in the context of the allocation of wealth into a portfolio of various assets. If all assets yield the same return with certainty, investors are indifferent across portfolios.
} 
where $\tilde{\delta}_{x m}$ is defined as:

$$
\tilde{\delta}_{x m}=\delta+\delta(1-\delta) \frac{H\left(\Pi_{x m}^{m}, \gamma_{X}\right)-H\left(\Pi_{x m}^{x}, \gamma_{M}\right)}{\delta H\left(\Pi_{x m}^{m}, \gamma_{X}\right)+(1-\delta) H\left(\Pi_{x m}^{x}, \gamma_{M}\right)}
$$

where $H\left(\Pi_{x m}^{i}, \gamma_{j}\right)$ is a function that is increasing and convex in both argument, with a positive cross-derivative. ${ }^{15}$ It is equal to one when $\gamma_{j}=0$ and goes from one to infinity as $\Pi_{x m}^{i}$ goes from zero to one. ${ }^{16}$

$\tilde{\delta}_{x m}$ reflects the effective bargaining weight of importer $m$ vis-a-vis exporter $x$, and is a function of the concavity of valuations of payoffs, the shares (10)-(11) and the formal weight $\delta$. The effective bargaining weight of the importer corresponds to the formal weight $\left(\tilde{\delta}_{x m}=\delta\right)$ only when agents have a linear valuation of profits $\left(\gamma_{X}=\gamma_{M}=0\right)$. Otherwise, (13) is an increasing function importer size, $\Pi_{x m}^{m}$, a decreasing function of the exporter size, $\Pi_{x m}^{x}$, a decreasing function of the importer's risk aversion, $\gamma_{M}$, and an increasing fucntion of the exporter's risk aversion, $\gamma_{X}$. Intuitively, failing to reach an agreement with a large importer leaves the exporter with low profits, and thus a high marginal valuation of profits as (2) is concave. As result, the exporter cares more about striking an agreement with a larger importer than with a smaller one.

(12) takes a simple form if demand is not price sensitive $(\rho=0)$. The price is then a simple average between the average production cost and the resale price:

$$
\bar{P}_{x m}=\tilde{\delta}_{x m} \bar{C}_{x m}+\left(1-\tilde{\delta}_{x m}\right) \bar{Z}_{m}
$$

A high effective bargaining weight of the importer brings the price close to the production cost, thus shifting the allocation of the margin between the final price and the cost towards the importer. The opposite is the case when the importer's effective weight is low.

When demand is price sensitive $(\rho>0)$, (12) takes the form of a quadratic polynomial in $\bar{P}_{x m}$. As long as the final price exceeds the marginal cost of production $\left(\bar{Z}_{m}>\overline{M C}_{x m}\right)$ the polynomial has one root between $\bar{C}_{x m}$ and $\bar{Z}_{m}$ and

\footnotetext{
${ }^{15}$ Specifically: $\partial H / \partial \Pi_{x m}^{i}>0, \partial^{2} H /\left(\partial \Pi_{x m}^{i}\right)^{2}>0, \partial H / \partial \gamma_{j}>0, \partial^{2} H /\left(\partial \gamma_{j}\right)^{2}>0$, $\partial^{2} H /\left(\partial \gamma_{j} \partial \Pi_{x m}^{i}\right)>0$.

${ }^{16}$ Formally we have:

$$
H\left(\Pi_{x m}^{i}, \gamma_{j}\right)=\frac{1}{1-\gamma_{j}} \frac{1}{\Pi_{x m}^{i}}\left[1-\left(1-\Pi_{x m}^{i}\right)^{1-\gamma_{j}}\right]
$$
}


another above $\bar{Z}_{m}$. We rule out the second root as it implies that the importer makes negative profits $\left(\bar{P}_{x m}>\bar{Z}_{m}\right)$. The first root by contrast implies that both the exporter and the importer make positive profits $\left(\bar{P}_{x m}>\bar{C}_{x m}\right.$ and $\left.\bar{Z}_{m}>\bar{P}_{x m}\right)$.

Our analysis shows that the steady state solution is a fixed point characterized by the shares of the exporter (importer) in their counterpart's payoff, (10)-(11), which are functions of the prices between them, and by the price (12) which is a function of the shares (10)-(11) through the effective bargaining weight (13). The steady-state solution is the fixed point of these relations. While we cannot derive an analytical solution for this fixed point in general, we can compute the solution for specific cases presented in section $5 .^{17}$

\subsection{Approximation around the steady state}

The next step of the solution method is to expand the first-order conditions (8) and (9) around the steady-state. Our analysis requires us to consider quadratic $\log$ approximations for two reasons. First, the extent of LCP $\beta_{x m}$ determines who bears the exchange rate risk outside of the steady state. Computing $\beta_{x m}$ then requires that we include the second moments of the equations through a quadratic approximation. Second, the preset component of the price, $P_{x m}^{f}$, differs from the steady state price $\bar{P}_{x m}$ in (12) in the presence of risk, as forward-looking agents take account of the second moments when setting the price. ${ }^{18}$ Specifically, the preset component of the price can be written as $P_{x m}^{f}=\bar{P}_{x m} \exp \left[\varrho \sigma^{2}\right]$ where $\varrho$ is a coefficient and $\sigma^{2}$ is proportional to the variances of the (log of the) shocks to the exchange rate, final prices, wages, and demand shifters. We denote the logarithms of the various variables by lower case letters.

As shown below, the extent of LCP $\beta_{x m}$ is computed using the quadratic approximation of (9) across all $x m$ pairs. The log of preset prices $p_{x m}^{f}$ can then be computed from the quadratic approximation of (8). In our analysis we focus on the first step and abstract from the second step for two reasons. First, solving

\footnotetext{
${ }^{17}$ The presence of decreasing returns to scale $(\lambda<1)$ implies that the size of the exogenous output for the $x m$ pair, $\bar{Q}_{x m}^{s e t}$ in (5), affects the marginal and average costs for the pair, making the analysis more complex. In the remainder of our analysis, we shut this dimension down by appropriately scaling the productivity $\bar{A}_{x m}$ to $\left(\bar{Q}_{x m}^{\text {set }}\right)^{1-\lambda}$, so that $\bar{Q}_{x m}^{\text {set }}$ and $\bar{A}_{x m}$ offset each other in the steady state marginal cost (6).

${ }^{18}$ This element is a standard feature in the analysis of optimal monetary policy in models where prices are set ex-ante by forward looking agents.
} 
for the invoicing shares does not require knowing the price gap between $p_{x m}^{f}$ and $\ln \left(\bar{P}_{x m}\right)$. Second, the gap is of the form $\varrho \sigma^{2}$ and can thus be set to be arbitrarily small by choosing a small variance of shocks. By contrast, the invoicing shares $\beta_{x m}$ are independent from the volatility of shocks (as long as this volatility is not zero). ${ }^{19}$

We expand (9) around the steady state with respect to the logs of the preset component of the price $p_{x m}^{f}$, the exogenous exchange rate $s$, the exogenous component of the input cost $w_{x}$, the exogenous final price $z_{m}$, and the exogenous component of demand $q_{x m}^{\text {set }} \cdot{ }^{20}$ We denote logs deviation from the steady state with hatted values: $\hat{z}_{m}=z_{m}-\ln \left[\bar{Z}_{m}\right]$.

The quadratic approximation of (9) leads to the following expression (the steps are presented in the appendix):

$$
\begin{aligned}
& 0=-\frac{\rho \bar{Z}_{m}}{\rho \bar{Z}_{m}+(1-\rho) \bar{P}_{x m}} \frac{E \hat{z}_{m} \hat{s}}{E \hat{s}^{2}}+\frac{\rho \overline{M C}_{x m}}{(1-\rho) \bar{P}_{x m}+\rho \overline{M C}_{x m}}\left(\frac{E \hat{w}_{x} \hat{s}}{E \hat{s}^{2}}+\zeta_{x}\right) \\
& +\frac{\rho \overline{M C}_{x m}}{(1-\rho) \bar{P}_{x m}+\rho \overline{M C}_{x m}} \frac{1-\lambda}{\lambda}\left(\frac{E \hat{q}_{x m}^{\text {set }} \hat{s}}{E \hat{s}^{2}}-\rho\left(\beta_{x m}-\eta_{x m}\right)\right) \\
& +\frac{(1-\rho) \bar{P}_{x m}}{\rho \bar{Z}_{m}+(1-\rho) \bar{P}_{x m}}\left(1-\beta_{x m}\right)+\frac{(1-\rho) \bar{P}_{x m}}{(1-\rho) \bar{P}_{x m}+\rho \overline{M C}_{x m}} \beta_{x m} \\
& +\gamma_{M}\left[\sum_{i=1}^{X} \Pi_{i m}^{i}\left(\begin{array}{c}
\frac{\bar{Z}_{m}}{\bar{Z}_{m}-\bar{P}_{i m}} \frac{E \hat{z}_{m} \hat{s}}{E \hat{S}^{2}}+\frac{\bar{P}_{i m}}{\bar{Z}_{m}-\bar{P}_{i m}}\left(1-\beta_{i m}\right) \\
+\frac{E \hat{q}_{i m} \hat{s}}{E \hat{s}^{2}}-\rho\left(\beta_{i m}-\eta_{i m}\right)
\end{array}\right)\right] \\
& -\gamma_{X}\left[\sum_{j=1}^{M} \Pi_{x j}^{j}\left(\begin{array}{c}
\frac{\bar{P}_{x j}}{\bar{P}_{x x}-\bar{C}_{x j}} \beta_{x j}-\frac{\bar{C}_{x j}}{\bar{P}_{x j}-\bar{C}_{x j}}\left(\frac{E \hat{w}_{x} \hat{s}}{E \hat{s}^{2}}+\zeta_{x}\right) \\
+\frac{\bar{P}_{x j}-\bar{M} \bar{C}_{x j}}{\bar{P}_{x j}-\bar{C}_{x j}}\left(\frac{E \hat{q}_{x j}^{s j} \hat{s}}{E \hat{s}^{2}}-\rho\left(\beta_{x j}-\eta_{x j}\right)\right)
\end{array}\right)\right]
\end{aligned}
$$

The first three rows of (14) reflect various aspects for the $x m$ pair that affect the optimal LCP. The first driver is the comovement between the final price and the exchange rate, $\left(E \hat{z}_{m} \hat{s}\right)\left(E \hat{s}^{2}\right)^{-1}$. If the final price moves in step with the exchange rate, the importer is willing to accept lower LCP. The intuition is that the importer can sell the goods at a higher final price when a depreciation of her currency raises the price she pays in her currency for imports. The second driver

\footnotetext{
${ }^{19}$ In technical terms, $\beta_{x m}$ is similar to a portfolio share in models of endogenous portolfio choice such as Tille and van Wincoop (2010). Such so-called "zero-order" shares depend not on the magnitude of volatility (as long as it is positive) but on the co-movements between asset returns and pricing kernels.

${ }^{20}$ The deviation of the price $p_{x m}^{f}$ from the steady state being proportional to the variance of shocks (i.e. "second order") it ends up dropping out of the approximation.
} 
is the comovement between the exporter's production cost and the exchange rate, either directly through importer input $\operatorname{costs} \zeta_{x}$ or indirectly through comovements between wages and the exchange rate, $\left(E \hat{w}_{x} \hat{s}\right)\left(E \hat{s}^{2}\right)^{-1}$. If production costs increase when the importer's currency weakens, the exporter is less willing to accept high LCP. The third driver is the impact of exchange rate movements on demand either through different degrees of LCP relative to competitors, $\beta_{x m}-\eta_{x m}$, which affects demand through relative prices, or through comovements between the exchange rate and demand shocks, $\left(E \hat{q}_{x m}^{s e t} \hat{s}\right)\left(E \hat{s}^{2}\right)^{-1}$. Such fluctuations in demand lead to volatile marginal costs of production, and hence a higher marginal cost on average, when the production technology is characterized by decreasing returns to scale $(\lambda<1)$. This is the "coalescing" motive of invoicing (Goldberg and Tille 2008).

The last two rows in (14) reflect how the interactions with partners other than $x$ and $m$ affect the extent of LCP for the $x m$ pair. These interactions are the ones between importer $m$ and all exporters (fourth row) and between exporter $x$ and all importers (fifth row). Intuitively, the deals reached with other counterparts affect the marginal utility of income of exporter $x$ and importer $m$ and thus the outcome of their bargaining. This spillover dimension is absent when the valuation of payoffs is linear, implying a constant marginal valuation $\left(\gamma_{X}=\gamma_{M}=0\right)$.

The overall solution of the model is given by the system (14) for each $x m$ pair. As each solution involves elements for all exporter-importer pairs in the last two terms, this makes for a complex system that has no analytical solution in general. We therefore focus on particular cases designed to highlight the importance of market structure among exporters and importers. The first case highlights the impact of exporter or importer fragmentation, and the second case considers the impact of heterogeneity among exporters and among importers.

\section{Numerical illustration of the results}

\subsection{Importer and exporters fragmentation}

Our first case focuses on the impact of the number of exporters, $X$, and importers, $M$, assuming that all individual exporters (importers) are identical. The shares (10)-(11) are then $\Pi_{x m}^{m}=1 / M$ and $\Pi_{x m}^{x}=1 / X$, and the effective bargaining 
weight (13) is:

$$
\tilde{\delta}=\delta+\delta(1-\delta) \frac{H\left(M^{-1}, \gamma_{X}\right)-H\left(X^{-1}, \gamma_{M}\right)}{\delta H\left(M^{-1}, \gamma_{X}\right)+(1-\delta) H\left(X^{-1}, \gamma_{M}\right)}
$$

As the price set between exporter $x$ and importer $m$ affects the quantity sold, we need to specify the reference price $R_{x m}^{m}$ in (5). We assume that the reference price is that set by other exporters, which in equilibrium is equal to $P_{x m}^{m}$, so that $r_{m b}^{f}=p_{x m}^{f}$ and $\eta_{x m}=\beta_{x m}$ as all exporters are identical. (5) implies that in equilibrium $Q_{x m}=Q_{x m}^{s e t}$. We denote the exogenous component of overall quantity traded in the steady state by $\bar{Q}^{\text {set }}$, so that $\bar{Q}_{x m}^{\text {set }}=\bar{Q}^{\text {set }} /(X M)$, and the marginal cost is $\overline{M C}=\lambda^{-1} \bar{W}$ (as all exporter-importer pairs are identical, we drop the $x$ and $m$ subscripts). Using (12) the steady state price $\bar{P}$ solves:

$$
\begin{aligned}
0= & \tilde{\delta}_{x m}\left(1-\frac{\rho}{\rho-1} \frac{\bar{Z}}{\bar{P}}\right)(\bar{P}-\bar{W}) \\
& -\left(1-\tilde{\delta}_{x m}\right)\left(\bar{P}-\frac{\rho}{\rho-1} \frac{1}{\lambda} \bar{W}\right)\left(\frac{\bar{Z}}{\bar{P}}-1\right)
\end{aligned}
$$

Turning to the optimal exposure to the exchange rate, the first-order condition (14) is written as:

$$
\begin{aligned}
0= & {\left[\text { Coef }_{1}+\text { Coef }_{2} \cdot \zeta\right] } \\
& +\left[\gamma_{M} \frac{\bar{Z}}{\bar{Z}-\bar{P}}-\frac{\rho \bar{Z}}{\rho \bar{Z}+(1-\rho) \bar{P}}\right] \frac{E \hat{z} \hat{s}}{E \hat{s}^{2}} \\
& + \text { Coef }_{2} \frac{E \hat{w} \hat{s}}{E \hat{s}^{2}}+\operatorname{Coef}_{3} \cdot \frac{E \hat{q}^{s e t} \hat{s}}{E \hat{s}^{2}} \\
& -\left[\text { Coef }_{1}-\frac{(1-\rho) \bar{P}}{(1-\rho) \bar{P}+\rho \overline{M C}}+\gamma_{x} \frac{\bar{P}}{\bar{P}-\bar{C}}\right] \beta
\end{aligned}
$$

where the various coefficients are:

$$
\begin{aligned}
\text { Coef }_{1} & =\gamma_{M} \frac{\bar{P}}{\bar{Z}-\bar{P}}+\frac{(1-\rho) \bar{P}}{\rho \bar{Z}+(1-\rho) \bar{P}} \\
\text { Coef }_{2} & =\gamma_{X} \frac{\bar{C}}{\bar{P}-\bar{C}}+\frac{\rho \overline{M C}}{(1-\rho) \bar{P}+\rho \overline{M C}} \\
\text { Coef }_{3} & =\gamma_{M}-\gamma_{X} \frac{\bar{P}}{\bar{P}-\bar{C}}+\gamma_{X} \frac{\bar{C}}{\bar{P}-\bar{C}} \frac{1}{\lambda}-\frac{\rho \overline{M C}}{(1-\rho) \bar{P}+\rho \overline{M C}} \frac{\lambda-1}{\lambda}
\end{aligned}
$$

We illustrate the economic significance of our results for prices and invoice currency choice through a numerical example. As a baseline specification, we assume an even formal bargaining power, $\delta=0.5$, and set both $\gamma_{X}$ and $\gamma_{M}$ to 
2. We set $\rho=2$, and assume that production exhibits constant returns to scale $(\lambda=1)$, and set the cost and price parameters at $\bar{W}=1, \bar{Q}^{\text {set }}=10$. We parametrize $\bar{Z}=2 \bar{W} / \lambda$ to ensure that it always exceeds the production cost. For this baseline case, we assume that input costs are insulated from the exchange rate: $\left(E \hat{w}_{x} \hat{s}\right)\left(E \hat{s}^{2}\right)^{-1}=\zeta_{x}=0$, and that prices and quantities do not comove with the exchange rate: $\left(E \hat{q}_{x m}^{\text {set }} \hat{s}\right)\left(E \hat{s}^{2}\right)^{-1}=\left(E \hat{z}_{m} \hat{s}\right)\left(E \hat{s}^{2}\right)^{-1}=0$. In a range of exercises we relax some of these restrictive conditions and explore the consequences of changing the respective assumptions.

The top-left panel of figure 1 shows the effective bargaining weight, $\tilde{\delta}_{x m}$, relative to the formal weight $\delta$, as a function of the numbers of importers $M$ and exporters $X$. Importers have a higher effective weight when they are more concentrated than exporters are, i.e. when $M$ is low or $X$ is high. Most of the impact of bargaining power takes place are relatively low values of $X$ and $M$.

The effective bargaining weight of the importer is reflected in the steady state price shown in the top-right panel. Importers who dominate the bargaining are able to secure a lower price. The bottom-left panel displays the value of individual transactions in the steady state. The exogenous component $\bar{Q}_{x b}^{\text {set }}=\bar{Q}^{\text {set }} /(X M)$ is equally reduced by a high number of importers or a high number of exporters. However, when importers are fragmented ( $M$ is high and $X$ is low) their bargaining weight is limited and they are charged a relatively high price. Conversely, they are charged a low price when fragmentation is on the exporters' side ( $M$ is low and $X$ is high). Therefore, small transactions in real terms have a higher nominal value when the small size reflects importer fragmentation than when it reflects exporter fragmentation.

The extent of LCP $\beta_{x m}$ is presented in the bottom-right panel. It follows a pattern similar to the steady-state price, with a higher exposure of importers to exchange rate movements (a lower $\beta_{x m}$ ) when importers have a high effective bargaining weight. This result can seem puzzling as it seems that importers take on more exposure to risk when they are more powerful. The reason is that they also benefit from low prices and thus get more of the joint surplus from trade contract negotiations. The marginal utility of importers' is then small relative to that of exporters, implying that the importers care relatively little about exchange rate fluctuations. Interestingly, a market structure where the extent of LCP $\beta_{x m}$ is high ( $M$ is high and $X$ is low) is also a market structure where the value of transactions (the price) is high. Therefore, there is a small (7.4\%) positive correlation across 
market structures between transaction value and the extent of LCP.

We now assess the sensitivity of the results to the model parameters. For brevity we focus on the steady state price and the extent of LCP. Figure 2 shows the case where the price and extent of LCP are decided only by the exporter, with the importer's formal weight $\delta$ being zero. The steady state price is brought all the way up to the final price $\bar{Z}$. The exporter reaps all the surplus and is willing to accept a large exchange rate exposure (a high $\beta_{x m}$ ). Again, the reason for the willingness to take on a large exposure to exchange rate risk stems from the low marginal utility on this decision. The degree of fragmentation among importers or exporters does not impact the price and extent of LCP.

Figure 3 shows that increasing the concavity of payoff valuation for all agents $\left(\gamma_{X}=\gamma_{M}=4\right)$ makes the pricing and invoicing pattern more sensitive to the market structure. Intuitively, agents are more sensitive towards failing to reach an agreement with a counterpart when this failure substantially affects their marginal utility. If we only increase the concavity of valuation for importers (Figure 4 with $\gamma_{X}=2$ and $\left.\gamma_{M}=4\right)$, the pricing and invoicing are more sensitive to the number of exporters but not to the number of importers (relative to the baseline case). A higher concavity of valuation on one side of the market thus magnifies the impact of fragmentation on the other side.

Increasing the sensitivity of demand to prices (Figure 5 with $\rho=5$ ) lowers the steady state price and the extent of LCP, and makes both prices and LCP insensitive to the fragmentation among agents, even though the effective bargaining share remains similar to the baseline. Importers in industries with a high pricesensitivity of demand benefit from a low steady state price and are willing to tolerate a higher exposure to exchange rate fluctuations as their marginal utility of payoff is low.

Figure 6 displays the case with decreasing returns to scale $(\lambda=0.75)$. We see that this has an impact on the steady state price, which is now higher, but does not matter much for the extent of LCP which is similar to Figure 1. Intuitively, a lower value of $\lambda$ raises the marginal cost for a given average cost. The right-hand side of (12) then becomes negative, which requires a higher steady state price.

Finally, we consider that exchange rate movements directly impact the cost of inputs in Figure $7\left(\zeta_{x}=0.5\right)$, so that a depreciation of the exporter's currency raises her production costs. While this reliance on imported inputs (or exchange rate sensitive costs) has little impact on the steady state price, it raises the extent of 
LCP substantially, and makes the LCP share less sensitive to the market structure. Intuitively, stabilizing the price in the importer's currency provides more of a hedging benefit to exporters, as a depreciation of their currency then increases their unit revenue and thus offsets the increase in costs.

To sum up, our analysis shows that the extent of fragmentation among importers and exporters impacts the effective bargaining weights, the prices, and the extent of LCP. Interestingly, a higher bargaining power for importers benefits them through a lower steady state price. This gives them high payoffs and thus lowers their marginal utility. This in turns make them more tolerant towards volatility and leads them to accept a high exposure to exchange rate fluctuations.

\subsection{Intra-group heterogeneity}

We now turn to the role of heterogeneity among exporter and importers. For simplicity, we assume that there are two exporters, denoted by $X 1$ and $X 2$, and two importers, denoted by $M 1$ and $M 2$. Without loss of generality we consider that exporter 1 and importer 1 are relatively large. Specifically, the steady values of the $Q_{x m}^{s e t}$ terms in (5) are:

$$
\begin{aligned}
& \bar{Q}_{X 1 M 1}^{\text {set }}=\alpha \psi \bar{Q}^{\text {set }} \quad ; \quad \bar{Q}_{X 1 M 2}^{\text {set }}=\alpha(1-\psi) \bar{Q}^{\text {set }} \\
& \bar{Q}_{X 2 M 1}^{\text {set }}=(1-\alpha) \psi \bar{Q}^{\text {set }} \quad ; \quad \bar{Q}_{X 2 M 2}^{\text {set }}=(1-\alpha)(1-\psi) \bar{Q}^{\text {set }}
\end{aligned}
$$

$\bar{Q}^{\text {set }}$ is the total quantity exchange in the steady state. The coefficients $\alpha \in[0.5,1]$ and $\psi \in[0.5,1]$ denote the sizes of larger exporter and the larger importer, respectively. The case of homogeneity ( $\alpha=\psi=0.5$ ) corresponds to the fragmentation case with $X=M=2$.

As in the previous example, we begin by specifying the reference price $R_{x m}^{m}$ in (5). We treat this reference price as an index of prices set by exporters to importer $m$, written as:

$$
R_{x m}^{m}=R_{m}^{m}=\left[\alpha\left[P_{X 1 m}\right]^{1-\rho}+(1-\alpha)\left[P_{X 2 m}\right]^{1-\rho}\right]^{\frac{1}{1-\rho}}
$$

where the first equality denotes that the reference price is the same for all exporters selling to a given importer. For simplicity we assume that the final price $Z_{m}$ and the input cost $w_{x}$ are the same for all importers and exporters.

The steady state solution takes the form of the pleasant exercise of solving 14 non-linear equations. The first two are the price indexes (17), one for each 
importer. The next four equations are the shares (10)-(11), then we have four effective bargaining weights (13), and finally four pricing equations (12). The specific equations are given in the appendix.

Turning to the determination of the optimal degree of LCP,we set $\hat{z}_{m}, \hat{q}_{x m}^{\text {set }}$, $\zeta_{x}$ and $\hat{w}_{x}$ to be the same for all $x m$ pairs for simplicity. A log linear approximation of the reference price $R_{x m}$ around the steady state implies that $\eta_{x m}=$ $\alpha \beta_{1 m}+(1-\alpha) \beta_{2 m}$. Using this result, we obtain four variants of the optimum LCP equation (14), one per importer-exporter pair. The relation for the 1,2 pair is presented in the appendix. The solution for the four invoicing shares is given by inverting a linear system of four equations.

We illustrate our results with a numerical example, taking the same baseline calibration as for the previous example. Figure 8 shows the effective bargaining weights relative to the formal weight, $\tilde{\delta}_{x m}-\delta$, as a function of the heterogeneity among exporters $(\alpha)$ and importers $(\beta)$ for all exporter-importer pairs. The top left panel considers the large importer's weight vis-a-vis the large exporter $\left(\tilde{\delta}_{X 1 M 1}\right)$, and shows that importer bargaining weight increases with importer heterogeneity (higher $\beta$ ) and decreases with the exporter heterogeneity (higher $\alpha$ ).

The bottom left panel shows that the large importer's bargaining weight vis-avis the small exporter $\left(\tilde{\delta}_{X 2 M 1}\right)$ is high and increases with importer heterogeneity, especially at high levels of heterogeneity. While it also increases with exporter heterogeneity, the effect is smaller. A mirror pattern is seen for the effective weight of the small importer vis-a-vis the large exporter $\left(\tilde{\delta}_{X 1 M 2}\right.$, top right panel), which is relatively insensitive to the importer heterogeneity but falls rapidly as the exporter heterogeneity increases. Finally, the small importer's weight vis-a-vis the small exporter $\left(\tilde{\delta}_{X 2 M 2}\right.$, bottom right panel $)$ is close to the formal weight and relatively insensitive to heterogeneity.

The pattern for the effective bargaining weights is mirrored in the steady state price (figure 9). The price is lower for sales to the larger importer (left panels) than for sales to the small importer (right panels). The gap is more pronounced when importer fragmentation is high, and for sales from the large exporter (top panels).

The extent of LCP, $\beta_{x m}$, is displayed in Figure 10 for the four importer-exporter pairs. Starting from the point of full homogeneity $(\alpha=\psi=0.5)$, the extent of LCP between the large importer and the large exporter (top left panel) falls with importer heterogeneity, but increases with exporter heterogeneity. This is a similar 
pattern to the one of the steady state price in Figure 9. When the importer can shift the surplus her way through a low steady state price, her marginal valuation of profits is low. The importer then is little affected by exchange rate volatility and more willing to be exposed to fluctuations resulting in low LCP. The similarity between the steady state price and the extent of LCP is also seen for sales from the large exporter to the small importer (top right panel). As the small importer carries less weight than the large one, she receives a higher price, but also a more limited exposure to exchange rate movements. The large importer also faces a smaller degree of LCP on sales from the small exporter (bottom left panel) than on sales from the large exporter (top left panel), reflecting the fact that she obtains a lower price on purchases from the smaller exporter. The extent of LCP between the small importer and small exporter (bottom right panel) increases with heterogeneity, but that pair has a limited impact on the aggregate pattern with high heterogeneity.

To obtain summary measures of the pricing and invoicing, we compute the average and standard deviation of the steady state price and extent of LCP across the four exporter-importer pairs, weighting each pair by its share in total steady state transaction value. The results are presented in Figure 11. Exporter heterogeneity raises the average price of traded goods (top left panel). While the cross-sectional dispersion of prices (top right panel) is raised by heterogeneity of either exporters or importers, the dispersion is increased more by exporter heterogeneity. The extent of heterogeneity has a substantial impact on the average degree of LCP (bottom left panel) which increases with exporter heterogeneity. Heterogeneity on either side of the market raises the dispersion of LCP shares.

As the market structure impacts the steady state price, and hence the steady state value of transactions, as well as the extent of LCP, we consider the linkage between the two by computing the coefficient of correlation across the four exporter-importer pairs between the steady state value of transactions and the extents of LCP (Figure 12). This correlation is negative when importer heterogeneity dominates, but turns positive as exporter heterogeneity raises.

Our numerical example shows that the market structure has a sizable impact on the effective bargaining weight, price, and extent of LCP across the various importer-exporter pairs. This impact is also observed in aggregate terms, as the average value and dispersion of prices and extents of LCP, as well as the correlation between invoicing and transaction size, vary depending on the degrees of heterogeneity among importers and exporters. 
We now consider the impact of varying the model parameters along the same lines as in the previous example. For brevity, we focus on the averages and standard deviations of steady state prices and the extent of LCP, as well as the correlation between transaction value and invoicing. In the case of unilateral decisions by the exporters $(\delta=0$, not reported for brevity), the steady state price goes to the final price and the exporter takes most of the exchange rate risk, as in the previous example. The pricing and invoicing pattern is not affected by heterogeneity on either side of the market.

Increasing the concavity of payoff valuation $\left(\gamma_{X}=\gamma_{M}=4\right)$ raises the average extent of LCP somewhat (Figure 13 bottom left panel) and increases the dispersion of prices and extent of LCP (right panels). The average value of prices and invoicing remains sensitive to the amount of heterogeneity on both sides of the market. The correlation between transaction value and invoicing remains close to the baseline case (Figure 14). If payoffs are more concave only for importers $\left(\gamma_{X}=2\right.$ and $\gamma_{M}=4$ ), the average price and extent of LCP are further increased (Figure 15 left panels).

Increasing the sensitivity of demand to prices $(\rho=5)$ substantially lower the average price and the average extent of LCP, as importers' marginal utility is then less sensitive to prices (Figure 17 left panels). The average price and invoicing is also much less sensitive to the market structure. In addition, the cross sectional dispersion of the two measures is reduced (right panels), and shifts the correlation between transaction value and extent of LCP towards positive values (Figure 18).

Introducing decreasing returns to scale $(\lambda=0.75)$ raises the average price and reduces the extent of LCP (Figure 19 left panels) and leads to more dispersion in prices (top right panel). The dispersion in invoicing is now mostly driven by importer heterogeneity. The market structure has a sizable impact on the average price, and a more moderate one on the average extent of LCP. The correlation between transaction value and extent of LCP shifts towards negative values (Figure 20). We finally consider a direct impact of the exchange rate on input costs $\left.\zeta_{x}=0.5\right)$. This has little impact on prices (Figure 21 top panel) and raises the average extent of LCP (bottom left panel) while lowering its dispersion somewhat. The sensitivity of the average price and invoicing to the market structure remains similar to the baseline case. The correlation between transaction value and invoicing remains close to the baseline case (Figure 22). 


\subsection{Implications from the model}

While our two specific examples focus on different dimensions of the model, our analysis provides broad lessons that are relevant for understanding pricing and invoicing patterns in international trade. These lessons arise when bargaining can occur between exporters and importers.

First, the analysis should encompass all the dimensions of the contract that are affected by bargaining. One may expect at first that a higher bargaining power of risk-averse importers would lead them to reduce their exchange rate exposure through higher LCP. Our analysis shows that the opposite is the case, as the higher bargaining weight is reflected in a steady state price more favorable to importers, which in turn reduces the marginal impact of exchange rate risk on importers payoffs and leads them to accept more exchange rate exposure. A different pattern would emerge if the bargaining took place only over the extent of LCP, with the preset price set unilaterally by the exporter, in which case a higher bargaining power of importers would raise the extent of LCP. These findings point to the need for more research targeted at understanding the specific structures of negotiations that occur between exporters and importers.

Second, the specific market structure matters not only at the level of individual transactions but also in aggregate terms, as shown by our second example. This insight points to the need for empirical studies of exchange rate exposure to understand the market structure at the micro level, even when the focus is on the aggregate extent of LCP.

Third, our examples show that the extent of LCP is higher in situations where exporters are more dominant, either because they are less fragmented (a low $X$ relative to $M$ in the first example), or because their side of the market is dominated by a few agents (a high $\alpha$ relative to $\psi$ in the second example).

Fourth, the sensitivity of pricing and invoicing to market characteristics is magnified when agents are more sensitive to risk, dampened in industries where demand is more price-sensitive, and increased when exchange rate movements affect exporters' costs.

Finally, the correlation between the value of specific transactions and their reliance on LCP depends on the market structure. The correlation is positive when large transactions reflect large exporters, but negative when they reflect large importers. 


\section{Conclusion}

This paper analyzes the determination of prices and exposure to exchange rate fluctuations among exporters and importers through a simple model of bargaining. This setting expands the theoretical analysis beyond the standard assumption of unilateral choice by the exporter. We show that the market structure, reflecting in the share of specific exporters and importers in each other's total profits, has a substantial impact on effective bargaining weights, prices, and exchange rate exposure. This impact is not limited to specific exporter-importer pairs but also affects the aggregate values of prices and exposure. A striking result of our analysis is that powerful agents end up being more exposed to exchange rate fluctuations. This reflects the fact that their power allows them to shift the steady state price in their favor, which lowers their marginal utility and makes exchange rate fluctuations less of a concern.

Our analysis is the first step towards building a bargaining view in the theory of international trade pricing under uncertainty. Under this view understanding aggregate prices requires one to take account of the microeconomic structure of the market, such as the degrees of fragmentation and heterogeneity among exporters and importers. A promising area of future research is to go beyond our Nash bargaining solution and get more detailed evidence on the specific process of interaction between importers and exporters in specific industries.

Another avenue for further work is to allow for prices to respond ex-post to cost movements. It is reasonable to expect that this response will be substantially affected by the market structure. Recall that the importer's currency is used for the invoicing when the importer's weight is low, as she is then faced with a high preset price, hence low profits and a high marginal valuation of profits. In line

with the finding of Gopinath, Itskhoki, and Rigobon (2010) that price adjustment is low for U.S. imports invoiced in dollars, a reasonable conjecture is that in such a situation the high marginal utility would also leads to limited movements of prices when they can be adjusted. 


\section{Appendix}

This technical appendix presents specific analytical points on the key aspects of the model and its solution. A complete presentation of the technical aspects of the paper is in an exhaustive technical appendix available on request.

\subsection{Derivatives of the joint surplus}

The derivatives with respect to the log of the fixed component of the price that enter (8) are:

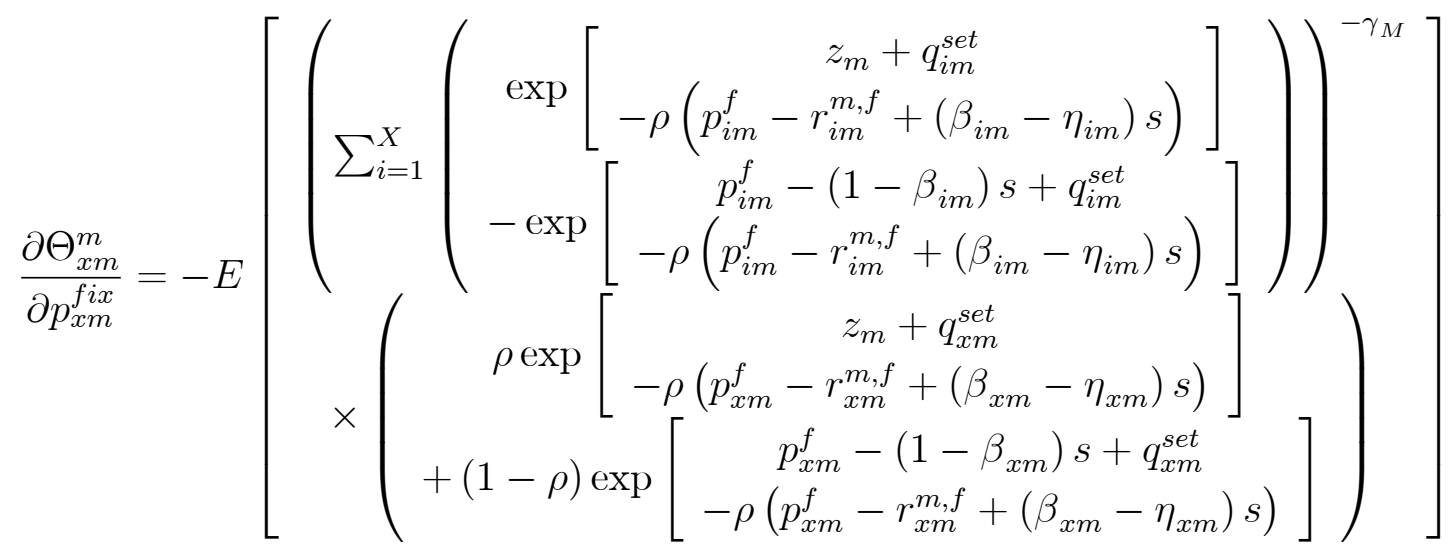

and:

$\frac{\partial \Theta_{x m}^{x}}{\partial p_{x m}^{f i x}}=E\left[\begin{array}{c}\left(\begin{array}{c}\exp \left[\begin{array}{c}p_{x j}^{f}+\beta_{x j} s+q_{x b}^{s e t} \\ -\rho\left(p_{x j}^{f}-r_{x j}^{j, f}+\left(\beta_{x j}-\eta_{x j}\right) s\right)\end{array}\right] \\ w_{x}+\zeta_{x} s+\frac{1}{\lambda} q_{x j}^{s e t} \\ -\exp \left[\begin{array}{c}(1-\rho) \exp \left[\begin{array}{c}(1 \\ -\frac{\rho}{\lambda}\left(p_{x j}^{f}-r_{x j}^{j, f}+\left(\beta_{x j}-\eta_{x j}\right) s\right)-\frac{1}{\lambda} a_{x j}\end{array}\right]\end{array}\right) \\ \times\left(\begin{array}{c}p_{x m}^{f}+\beta_{x m} s+q_{x m}^{s e t} \\ -\rho\left(p_{x m}^{f}-r_{x m}^{m, f}+\left(\beta_{x m}-\eta_{x m}\right) s\right)\end{array}\right] \\ +\frac{\rho}{\lambda} \exp \left[\begin{array}{c}w_{x}+\zeta_{x} s+\frac{1}{\lambda} q_{x m}^{s e t} \\ -\frac{\rho}{\lambda}\left(p_{x m}^{f}-r_{x m}^{m, f}+\left(\beta_{x m}-\eta_{x m}\right) s\right)-\frac{1}{\lambda} a_{x m}\end{array}\right]\end{array}\right)\end{array}\right]$ 
The derivatives with respect to the exchange rate exposure in (9) are:

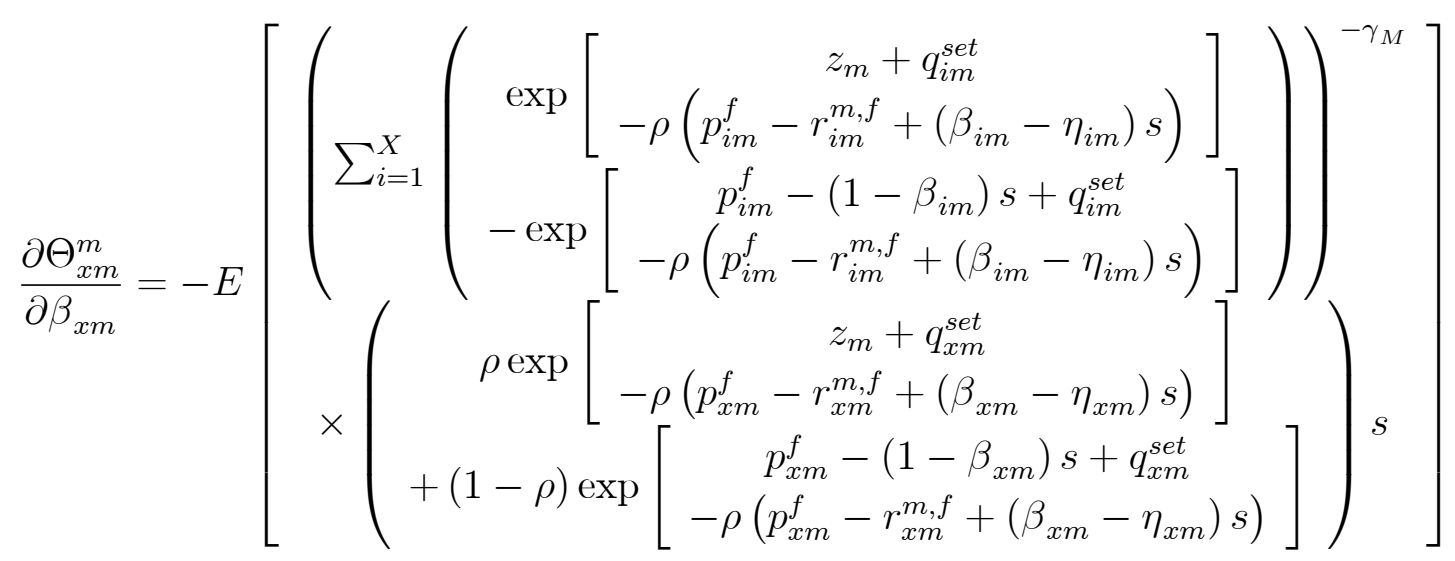

and:

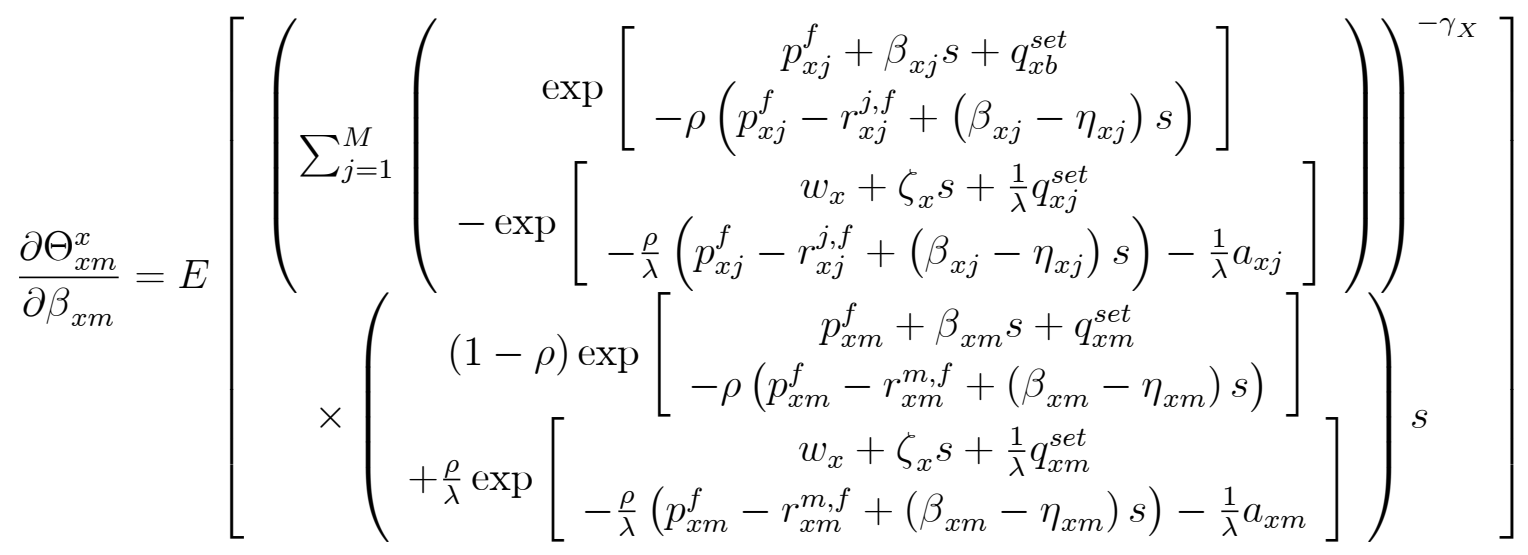

\subsection{Quadratic approximation}

To write a quadratic approximation of (9), we first notice that left- and righthand sides are expressions of the form (the detailed expression for (9) is given in a long technical appendix):

$$
\begin{aligned}
\Phi= & \frac{\delta_{1}}{1-\gamma_{1}} E\left[\left(\sum_{s 1}(\exp [a]-\exp [b])\right)^{-\gamma_{2}}\left(c_{1} \exp [c]+h_{1} \exp [h]\right) s\right] \\
& \times\left[E\left(\sum_{s 2}(\exp [d]-\exp [e])\right)^{1-\gamma_{1}}-E\left(\begin{array}{c}
\sum_{s 2}(\exp [d]-\exp [e]) \\
-(\exp [f]-\exp [g])
\end{array}\right)^{1-\gamma_{1}}\right]
\end{aligned}
$$


Bearing in mind that we expand around $\bar{s}=0$ and that $E \hat{s}=0$, we write:

$$
\begin{aligned}
\Phi= & \frac{\delta_{1}}{1-\gamma_{1}}\left(\sum_{s 2}(\bar{D}-\bar{E})\right)^{1-\gamma_{1}}\left(c_{1} \bar{C}+h_{1} \bar{H}\right)\left(\sum_{s 1}(\bar{A}-\bar{B})\right)^{-\gamma_{2}} \\
& \times\left[1-\left(1-\frac{\bar{F}-\bar{G}}{\sum_{s 2}(\bar{D}-\bar{E})}\right)^{1-\gamma_{1}}\right] E\left[\begin{array}{c}
-\gamma_{2}\left(\sum_{s 1}(\bar{A}-\bar{B})\right)^{-1}\left(\sum_{s 1}(\bar{A} \hat{a}-\bar{B} \hat{b})\right) \hat{s} \\
+\left(c_{1} \bar{C}+h_{1} \bar{H}\right)^{-1}\left(c_{1} \bar{C} \hat{c}+h_{1} \bar{H} \hat{h}\right) \hat{s}
\end{array}\right]
\end{aligned}
$$

We now apply this to the left-hand side of (9). The various elements are:

$$
\begin{aligned}
s 1 & =i=1 \ldots X \quad ; \quad s 2=j=1 \ldots M \\
\delta_{1} & =\delta \quad ; \quad \gamma_{1}=\gamma_{X} \quad ; \quad \gamma_{2}=\gamma_{M} \\
c_{1} & =\rho \quad ; \quad h_{1}=1-\rho \\
a & =z_{m}+q_{i m}^{s e t}-\rho\left(p_{i m}^{f}-r_{i m}^{m, f}+\left(\beta_{i m}-\eta_{i m}\right) s\right) \\
b & =p_{i m}^{f}-\left(1-\beta_{i m}\right) s+q_{i m}^{s e t}-\rho\left(p_{i m}^{f}-r_{i m}^{m, f}+\left(\beta_{i m}-\eta_{i m}\right) s\right) \\
c & =z_{m}+q_{x m}^{s e t}-\rho\left(p_{x m}^{f}-r_{x m}^{m, f}+\left(\beta_{x m}-\eta_{x m}\right) s\right) \\
d & =p_{x j}^{f}+\beta_{x j} s+q_{x j}^{s e t}-\rho\left(p_{x j}^{f}-r_{x j}^{j, f}+\left(\beta_{x j}-\eta_{x j}\right) s\right) \\
e & =w_{x}+\zeta_{x} s+\frac{1}{\lambda} q_{x j}^{s e t}-\frac{\rho}{\lambda}\left(p_{x j}^{f}-r_{x j}^{j, f}+\left(\beta_{x j}-\eta_{x j}\right) s\right)-\frac{1}{\lambda} a_{x j} \\
f & =p_{x m}^{f}+\beta_{x m} s+q_{x m}^{s e t}-\rho\left(p_{x m}^{f}-r_{x m}^{m, f}+\left(\beta_{x m}-\eta_{x m}\right) s\right) \\
g & =w_{x}+\zeta_{x} s+\frac{1}{\lambda} q_{x m}^{s e t}-\frac{\rho}{\lambda}\left(p_{x m}^{f}-r_{x m}^{m, f}+\left(\beta_{x m}-\eta_{x m}\right) s\right)-\frac{1}{\lambda} a_{x m} \\
h & =p_{x m}^{f}-\left(1-\beta_{x m}\right) s+q_{x m}^{s e t}-\rho\left(p_{x m}^{f}-r_{x m}^{m, f}+\left(\beta_{x m}-\eta_{x m}\right) s\right)
\end{aligned}
$$

As all the pre-set component of all prices deviate from the steady-state allocation only because of second moments, we can omit the various $p^{f}$ and $r^{j, f}$ from the quadratic elements. We also recall that $\hat{a}_{x m}=0$ as $A_{x m}$ is constant. The quadratic approximation of the left-hand side is then:

$$
\begin{aligned}
& \frac{\delta}{1-\gamma_{X}}\left(\sum_{i=1}^{X}\left(\bar{Z}_{m}-\bar{P}_{i m}\right) \bar{Q}_{i m}^{s e t}\left(\bar{R}_{i m}^{m}\right)^{\rho}\left(\bar{P}_{i m}\right)^{-\rho}\right)^{-\gamma_{M}} \\
& \times\left(\sum_{j=1}^{M}\left(\bar{P}_{x j}-\bar{W}_{x}\left(\bar{A}_{x j}\right)^{-\frac{1}{\lambda}}\left(\bar{Q}_{x j}^{s e t}\right)^{\frac{1-\lambda}{\lambda}}\left(\bar{R}_{x j}^{j}\right)^{\rho \frac{1-\lambda}{\lambda}}\left(\bar{P}_{x j}\right)^{-\rho \frac{1-\lambda}{\lambda}}\right) \bar{Q}_{x j}^{s e t}\left(\bar{R}_{x j}^{j}\right)^{\rho}\left(\bar{P}_{x j}\right)^{-\rho}\right)^{1-\gamma_{X}} \\
& \times\left(\rho \bar{Z}_{m}+(1-\rho) \bar{P}_{x m}\right) \bar{Q}_{x m}^{s e t}\left(\bar{R}_{x m}^{m}\right)^{\rho}\left(\bar{P}_{x m}\right)^{-\rho}\left[1-\left(1-\Pi_{x m}^{m}\right)^{1-\gamma_{X}}\right] \\
& \times E\left[\begin{array}{c}
\left.-\gamma_{M}\left(\sum_{i=1}^{X} \Pi_{i m}^{i}\left(\frac{\bar{Z}_{m}}{\bar{Z}_{m}-\bar{P}_{i m}} \frac{E \hat{z}_{m} \hat{s}}{E \hat{s}^{2}}+\frac{\bar{P}_{i m}}{\bar{Z}_{m}-\bar{P}_{i m}}\left(1-\beta_{i m}\right)+\frac{E \hat{q}_{i m}^{s e} \hat{s}}{E \hat{s}^{2}}-\rho\left(\beta_{i m}-\eta_{i m}\right)\right)\right) E \hat{s}^{2}\right] \\
\quad+\left(\frac{\rho \bar{Z}_{m}}{\rho \bar{Z}_{m}+(1-\rho) \bar{P}_{x m}} \frac{E \hat{z}_{m} \hat{s}}{E \hat{s}^{2}}-\frac{(1-\rho) \bar{P}_{x m}}{\rho \bar{Z}_{m}+(1-\rho) \bar{P}_{x m}}\left(1-\beta_{x m}\right)+\frac{E \hat{q}_{x x}^{s e t} \hat{s}}{E \hat{s}^{2}}-\rho\left(\beta_{x m}-\eta_{x m}\right)\right) E \hat{s}^{2}
\end{array}\right]
\end{aligned}
$$


We now turn to the right-hand side of (9). The various elements are:

$$
\begin{aligned}
s 1 & =j=1 \ldots M \quad ; \quad s 2=i=1 \ldots X \\
\delta_{1} & =1-\delta \quad ; \quad \gamma_{1}=\gamma_{M} \quad ; \quad \gamma_{2}=\gamma_{X} \\
c_{1} & =1-\rho \quad ; \quad h_{1}=\frac{\rho}{\lambda} \\
a & =p_{x j}^{f}+\beta_{x j} s+q_{x j}^{s e t}-\rho\left(p_{x j}^{f}-r_{x j}^{j, f}+\left(\beta_{x j}-\eta_{x j}\right) s\right) \\
b & =w_{x}+\zeta_{x} s+\frac{1}{\lambda} q_{x j}^{s e t}-\frac{\rho}{\lambda}\left(p_{x j}^{f}-r_{x j}^{j, f}+\left(\beta_{x j}-\eta_{x j}\right) s\right)-\frac{1}{\lambda} a_{x j} \\
c & =p_{x m}^{f}+\beta_{x m} s+q_{x m}^{s e t}-\rho\left(p_{x m}^{f}-r_{x m}^{m, f}+\left(\beta_{x m}-\eta_{x m}\right) s\right) \\
d & =z_{m}+q_{i m}^{s e t}-\rho\left(p_{i m}^{f}-r_{i m}^{m, f}+\left(\beta_{i m}^{d}-\eta_{i m}^{d}\right) s^{d}\right) \\
e & =p_{i m}^{f}-\left(1-\beta_{i m}\right) s+q_{i m}^{s e t}-\rho\left(p_{i m}^{f}-r_{i m}^{m, f}+\left(\beta_{i m}-\eta_{i m}\right) s\right) \\
f & =z_{m}+q_{x m}^{s e t}-\rho\left(p_{x m}^{f}-r_{x m}^{m, f}+\left(\beta_{x m}-\eta_{x m}\right) s\right) \\
g & =p_{x m}^{f}-\left(1-\beta_{x m}\right) s+q_{x m}^{s e t}-\rho\left(p_{x m}^{f}-r_{x m}^{m, f}+\left(\beta_{x m}-\eta_{x m}\right) s\right) \\
h & =w_{x}+\zeta_{x} s+\frac{1}{\lambda} q_{x m}^{s e t}-\frac{\rho}{\lambda}\left(p_{x m}^{f}-r_{x m}^{m, f}+\left(\beta_{x m}-\eta_{x m}\right) s\right)-\frac{1}{\lambda} a_{x m}
\end{aligned}
$$

The quadratic approximation of the right-hand side is then:

$$
\begin{aligned}
& \frac{1-\delta}{1-\gamma_{M}}\left(\sum_{i=1}^{X}\left(\bar{Z}_{m}-\bar{P}_{i m}\right) \bar{Q}_{i m}^{s e t}\left(\bar{R}_{i m}^{m}\right)^{\rho}\left(\bar{P}_{i m}\right)^{-\rho}\right)^{1-\gamma_{M}} \\
& \times\left(\sum_{j=1}^{M}\left(\bar{P}_{x j}-\bar{W}_{x}\left(\bar{A}_{x j}\right)^{-\frac{1}{\lambda}}\left(\bar{Q}_{x j}^{s e t}\right)^{\frac{1-\lambda}{\lambda}}\left(\bar{R}_{x j}^{j}\right)^{\rho \frac{1-\lambda}{\lambda}}\left(\bar{P}_{x j}\right)^{-\rho \frac{1-\lambda}{\lambda}}\right) \bar{Q}_{x j}^{s e t}\left(\bar{R}_{x j}^{j}\right)^{\rho}\left(\bar{P}_{x j}\right)^{-\rho}\right)^{-\gamma_{X}} \\
& \times\left((1-\rho) \bar{P}_{x m}+\rho \overline{M C}_{x m}\right) \bar{Q}_{x m}^{s e t}\left(\bar{R}_{x m}^{m}\right)^{\rho}\left(\bar{P}_{x m}\right)^{-\rho}\left[1-\left(1-\Pi_{x m}^{x}\right)^{1-\gamma_{M}}\right] \\
& \times E\left[\begin{array}{c}
-\gamma_{x}\left(\sum_{j=1}^{M} \Pi_{x j}^{j}\left(\begin{array}{c}
\frac{\bar{P}_{x j}}{\bar{P}_{x j}-\bar{C}_{x j}}\left[\beta_{x j}+\frac{E \hat{q}_{x j}^{s e t} \hat{s}}{E \hat{s}^{2}}-\rho\left(\beta_{x j}-\eta_{x j}\right)\right] \\
-\frac{\bar{C}_{x b}}{\bar{P}_{x j}-\bar{C}_{x j}}\left[\frac{E \hat{w}_{x} \hat{s}}{E \hat{s}^{2}}+\zeta_{x}+\frac{1}{\lambda} \frac{E \hat{q}_{x j}^{s e t} \hat{s}}{E \hat{s}^{2}}-\frac{\rho}{\lambda}\left(\beta_{x j}-\eta_{x j}\right)\right]
\end{array}\right)\right) E \hat{s}^{2} \\
+\left(\begin{array}{c}
\frac{(1-\rho) \bar{P}_{x m}}{(1-\rho) \bar{P}_{x m}+\rho \overline{M C}_{x m}}\left[\beta_{x m}+\frac{E \hat{q}_{x m}^{s e t} \hat{s}}{E \hat{s}^{2}}-\rho\left(\beta_{x m}-\eta_{x m}\right)\right] \\
+\frac{\rho \overline{M C}_{x m}}{(1-\rho) \bar{P}_{x m}+\rho \overline{M C_{x m}}}\left[\frac{E \hat{w}_{x} \hat{s}}{E \hat{s}^{2}}+\zeta_{x}+\frac{1}{\lambda} \frac{E \hat{q}_{x m}^{s e} \hat{s}}{E \hat{s}^{2}}-\frac{\rho}{\lambda}\left(\beta_{x m}-\eta_{x m}\right)\right]
\end{array}\right) E \hat{s}^{2}
\end{array}\right]
\end{aligned}
$$


Combining our results, the approximation of (9) is written as:

$$
\begin{aligned}
0= & \gamma_{M}\left(\sum_{i=1}^{X} \Pi_{i m}^{i}\left(\frac{\bar{Z}_{m}}{\bar{Z}_{m}-\bar{P}_{i m}} \frac{E \hat{z}_{m} \hat{s}}{E \hat{s}^{2}}+\frac{\bar{P}_{i m}}{\bar{Z}_{m}-\bar{P}_{i m}}\left(1-\beta_{i m}\right)+\frac{E \hat{q}_{i m}^{s e t} \hat{s}}{E \hat{s}^{2}}-\rho\left(\beta_{i m}-\eta_{i m}\right)\right)\right) \\
& -\gamma_{X}\left(\sum _ { j = 1 } ^ { M } \Pi _ { x j } ^ { j } \left(-\frac{\bar{C}_{x j}}{\bar{P}_{x j}-\bar{C}_{x j}}\left[\bar{C}_{x j}+\frac{E \hat{q}_{x j}^{s e} \hat{s}}{E \hat{s}^{2}}-\rho\left(\beta_{x j}-\eta_{x j}\right)\right]\right.\right. \\
E \hat{s}^{2} & \left.\left.\left.+\zeta_{x}+\frac{1}{\lambda} \frac{E \hat{q}_{x j}^{s e t} \hat{s}}{E \hat{s}^{2}}-\frac{\rho}{\lambda}\left(\beta_{x j}-\eta_{x j}\right)\right]\right)\right) \\
& -\frac{\rho \bar{Z}_{m}}{\rho \bar{Z}_{m}+(1-\rho) \bar{P}_{x m}} \frac{E \hat{z}_{m} \hat{s}}{E \hat{s}^{2}}+\frac{(1-\rho) \bar{P}_{x m}}{\rho \bar{Z}_{m}+(1-\rho) \bar{P}_{x m}}\left(1-\beta_{x m}\right)-\frac{E \hat{q}_{x m}^{s e t} \hat{s}}{E \hat{s}^{2}}+\rho\left(\beta_{x m}-\eta_{x m}\right) \\
& +\frac{(1-\rho) \bar{P}_{x m}}{(1-\rho) \bar{P}_{x m}+\rho \overline{M C}_{x m}}\left[\beta_{x m}+\frac{E \hat{q}_{x m}^{s e t} \hat{s}}{E \hat{s}^{2}}-\rho\left(\beta_{x m}-\eta_{x m}\right)\right] \\
& +\frac{\rho \overline{M C}_{x m}}{(1-\rho) \bar{P}_{x m}+\rho \overline{M C}_{x m}}\left[\frac{E \hat{w}_{x} \hat{s}}{E \hat{s}^{2}}+\zeta_{x}+\frac{1}{\lambda} \frac{E \hat{q}_{x m}^{s e t} \hat{s}}{E \hat{s}^{2}}-\frac{\rho}{\lambda}\left(\beta_{x m}-\eta_{x m}\right)\right]
\end{aligned}
$$

which is (14) in the text after re-arranging terms.

\subsection{Intra-group heterogeneity}

The first two equations are the price indexes (17):

$$
\begin{aligned}
& \bar{R}_{M 1}=\left[\alpha\left[\bar{P}_{X 1 M 1}\right]^{1-\rho}+(1-\alpha)\left[\bar{P}_{X 2 M 1}\right]^{1-\rho}\right]^{\frac{1}{1-\rho}} \\
& \bar{R}_{M 2}=\left[\alpha\left[\bar{P}_{X 1 M 2}\right]^{1-\rho}+(1-\alpha)\left[\bar{P}_{X 2 M 2}\right]^{1-\rho}\right]^{\frac{1}{1-\rho}}
\end{aligned}
$$

where we dropped the superscripts on the $\bar{R}$ for simplicity. The four shares between importers and exporters $(10)-(11)$ are (recall that $\Pi_{x m}^{M 2}=1-\Pi_{x m}^{M 1}$, and $\Pi_{x m}^{X 2}=$ 
$1-\Pi_{x m}^{X 1}$

$$
\begin{aligned}
\Pi_{X 1 M 1}^{M 1}= & \frac{1}{1+\frac{\left(\bar{P}_{X 1 M 2}-\bar{W}\left(\bar{R}_{M 2}\right)^{\rho \frac{1-\lambda}{\lambda}}\left(\bar{P}_{X 1 M 2}\right)^{-\rho \frac{1-\lambda}{\lambda}}\right)(1-\psi)\left(\bar{R}_{M 2}\right)^{\rho}\left(\bar{P}_{X 1 M 2}\right)^{-\rho}}{\left(\bar{P}_{X 1 M 1}-\bar{W}\left(\bar{R}_{M 1}\right)^{\rho \frac{1-\lambda}{\lambda}}\left(\bar{P}_{X 1 M 1}\right)^{-\rho \frac{1-\lambda}{\lambda}}\right) \psi\left(\bar{R}_{M 1}\right)^{\rho}\left(\bar{P}_{X 1 M 1}\right)^{-\rho}}} \\
\Pi_{X 2 M 1}^{M 1}= & \frac{1}{1+\frac{\left(\bar{P}_{X 2 M 2}-\bar{W}\left(\bar{R}_{M 2}\right)^{\rho \frac{1-\lambda}{\lambda}}\left(\bar{P}_{X 2 M 2}\right)^{-\rho \frac{1-\lambda}{\lambda}}\right)(1-\psi)\left(\bar{R}_{M 2}\right)^{\rho}\left(\bar{P}_{X 2 M 2}\right)^{-\rho}}{\left(\bar{P}_{X 2 M 1}-\bar{W}\left(\bar{R}_{M 1}\right)^{\rho \frac{1-\lambda}{\lambda}}\left(\bar{P}_{X 2 M 1}\right)^{-\rho \frac{1-\lambda}{\lambda}}\right) \psi\left(\bar{R}_{M 1}\right)^{\rho}\left(\bar{P}_{X 2 M 1}\right)^{-\rho}}} \\
\Pi_{X 1 M 1}^{X 1}= & \frac{1}{1+\frac{\left(\bar{Z}-\bar{P}_{X 2 M 1}\right)(1-\alpha)\left(\bar{P}_{X 2 M 1}\right)^{-\rho}}{\left(\bar{Z}_{-} \bar{P}_{X 1 M 1}\right) \alpha\left(\bar{P}_{X 1 M 1}\right)^{-\rho}}} \\
\Pi_{X 1 M 2}^{X 1}= & \frac{1}{1+\frac{\left(\bar{Z}-\bar{P}_{X 2 M 2}\right)(1-\alpha)\left(\bar{P}_{X 2 M 2}\right)^{-\rho}}{\left(\bar{Z}_{-} \bar{P}_{X 1 M 2}\right) \alpha\left(\bar{P}_{X 1 M 2}\right)^{-\rho}}}
\end{aligned}
$$

The four effective bargaining weights (13) are:

$$
\begin{aligned}
\tilde{\delta}_{X 1 M 1} & =\frac{1}{1+\frac{(1-\delta) H\left(\Pi_{X 1 M 1}^{X 1}, \gamma_{M}\right)}{\delta H\left(\Pi_{X 1 M 1}^{M 1}, \gamma_{X}\right)}} \\
\tilde{\delta}_{X 1 M 2} & =\frac{1}{1+\frac{(1-\delta) H\left(\Pi_{X 1 M 2}^{X 1}, \gamma_{M}\right)}{\delta H\left(\left(1-\Pi_{X 1 M 1}^{M 1}\right), \gamma_{X}\right)}} \\
\tilde{\delta}_{X 2 M 1} & =\frac{1}{1+\frac{(1-\delta) H\left(\left(1-\Pi_{X 1 M 1}^{X 1}\right), \gamma_{M}\right)}{\delta H\left(\Pi_{X 2 M 1}^{M 1}, \gamma_{X}\right)}} \\
\tilde{\delta}_{X 2 M 2} & =\frac{1}{1+\frac{(1-\delta) H\left(\left(1-\Pi_{X 1 M 2}^{X 1}\right), \gamma_{M}\right)}{\delta H\left(\left(1-\Pi_{X 2 M 1}^{M 1}\right), \gamma_{X}\right)}}
\end{aligned}
$$

Finally, we have four pricing equations (12). The specific equations are given in the appendix. For the $X 1 M 1$ pair we write:

$$
\begin{aligned}
& \tilde{\delta}_{X 1 M 1}\left(\bar{P}_{X 1 M 1}-\frac{\rho}{\rho-1} \bar{Z}\right)\left(\bar{P}_{X 1 M 1}-\bar{W}\left(\bar{R}_{M 1}\right)^{\rho \frac{1-\lambda}{\lambda}}\left(\bar{P}_{X 1 M 1}\right)^{-\rho \frac{1-\lambda}{\lambda}}\right) \\
= & \left(1-\tilde{\delta}_{X 1 M 1}\right)\left(\bar{P}_{X 1 M 1}-\frac{\rho}{\rho-1} \frac{1}{\lambda} \bar{W}\left(\bar{R}_{M 1}\right)^{\rho \frac{1-\lambda}{\lambda}}\left(\bar{P}_{X 1 M 1}\right)^{-\rho \frac{1-\lambda}{\lambda}}\right)\left(\bar{Z}-\bar{P}_{X 1 M 1}\right)
\end{aligned}
$$


For the $X 1 M 2$ pair we write:

$$
\begin{aligned}
& \tilde{\delta}_{X 1 M 2}\left(\bar{P}_{X 1 M 2}-\frac{\rho}{\rho-1} \bar{Z}\right)\left(\bar{P}_{X 1 M 2}-\bar{W}\left(\bar{R}_{M 2}\right)^{\rho \frac{1-\lambda}{\lambda}}\left(\bar{P}_{X 1 M 2}\right)^{-\rho \frac{1-\lambda}{\lambda}}\right) \\
= & \left(1-\tilde{\delta}_{X 1 M 2}\right)\left(\bar{P}_{X 1 M 2}-\frac{\rho}{\rho-1} \frac{1}{\lambda} \bar{W}\left(\bar{R}_{M 2}\right)^{\rho \frac{1-\lambda}{\lambda}}\left(\bar{P}_{X 1 M 2}\right)^{-\rho \frac{1-\lambda}{\lambda}}\right)\left(\bar{Z}-\bar{P}_{X 1 M 2}\right)
\end{aligned}
$$

For the $X 2 M 1$ pair we write:

$$
\begin{aligned}
& \tilde{\delta}_{X 2 M 1}\left(\bar{P}_{X 2 M 1}-\frac{\rho}{\rho-1} \bar{Z}\right)\left(\bar{P}_{X 2 M 1}-\bar{W}\left(\bar{R}_{M 1}\right)^{\rho \frac{1-\lambda}{\lambda}}\left(\bar{P}_{X 2 M 1}\right)^{-\rho \frac{1-\lambda}{\lambda}}\right) \\
= & \left(1-\tilde{\delta}_{X 2 M 1}\right)\left(\bar{P}_{X 2 M 1}-\frac{\rho}{\rho-1} \frac{1}{\lambda} \bar{W}\left(\bar{R}_{M 1}\right)^{\rho \frac{1-\lambda}{\lambda}}\left(\bar{P}_{X 2 M 1}\right)^{-\rho \frac{1-\lambda}{\lambda}}\right)\left(\bar{Z}-\bar{P}_{X 2 M 1}\right)
\end{aligned}
$$

For the $X 2 M 2$ pair we write:

$$
\begin{aligned}
& \tilde{\delta}_{X 2 M 2}\left(\bar{P}_{X 2 M 2}-\frac{\rho}{\rho-1} \bar{Z}\right)\left(\bar{P}_{X 2 M 2}-\bar{W}\left(\bar{R}_{M 2}\right)^{\rho \frac{1-\lambda}{\lambda}}\left(\bar{P}_{X 2 M 2}\right)^{-\rho \frac{1-\lambda}{\lambda}}\right) \\
= & \left(1-\tilde{\delta}_{X 2 M 2}\right)\left(\bar{P}_{X 2 M 2}-\frac{\rho}{\rho-1} \frac{1}{\lambda} \bar{W}\left(\bar{R}_{M 2}\right)^{\rho \frac{1-\lambda}{\lambda}}\left(\bar{P}_{X 2 M 2}\right)^{-\rho \frac{1-\lambda}{\lambda}}\right)\left(\bar{Z}-\bar{P}_{X 2 M 2}\right)
\end{aligned}
$$

There are four variants of (14) for the four importer-exporter pairs. For instance, the one for the extent of LCP between importer $M 1$ and exporter $X 2$ 
is:

$$
\begin{aligned}
& 0=-\gamma_{X} \Pi_{X 1 M 1}^{M 1}\left[\begin{array}{c}
\left(\frac{\bar{P}_{X 1 M 1}}{\bar{P}_{X 1 M 1}-\bar{C}_{X 1 M 1}}-\frac{1}{\lambda} \frac{\bar{C}_{X 1 M 1}}{\bar{P}_{X 1 M 1}-\bar{C}_{X 1 M 1}}\right) \rho \alpha \\
+\frac{\bar{P}_{X 1 M 1}}{\bar{P}_{X 1 M 1}-\bar{C}_{X 1 M 1}}(1-\rho)+\frac{\rho}{\lambda} \frac{\bar{C}_{X 1 M 1}}{\bar{P}_{X 1 M 1}-\bar{C}_{X 1 M 1}}
\end{array}\right] \beta_{X 1 M 1}
\end{aligned}
$$

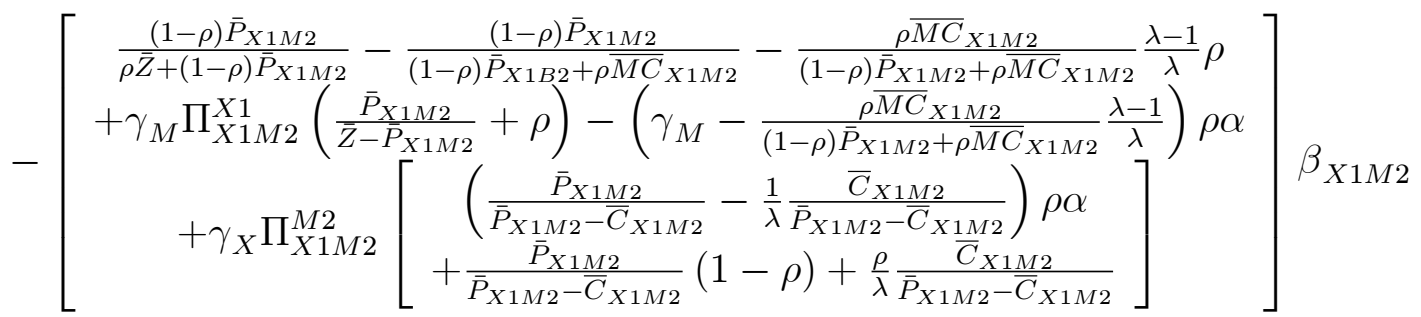

$$
\begin{aligned}
& -\gamma_{X} \Pi_{X 1 M 1}^{M 1}\left(\frac{\bar{P}_{X 1 M 1}}{\bar{P}_{X 1 B 1}-\bar{C}_{X 1 M 1}}-\frac{1}{\lambda} \frac{\bar{C}_{X 1 M 1}}{\bar{P}_{X 1 M 1}-\bar{C}_{X 1 M 1}}\right) \rho(1-\alpha) \beta_{X 2 M 1} \\
& -\left[\begin{array}{c}
\gamma_{M} \Pi_{X 2 M 2}^{X 2}\left(\frac{\bar{P}_{X 2 M 2}}{\bar{Z}-\bar{P}_{X 2 M 2}}+\rho\right)-\left(\gamma_{M}-\frac{\rho \overline{M C}_{X 1 M 2}}{(1-\rho) \bar{P}_{X 1 M 2}+\rho \bar{M}_{X 1 M 2}} \frac{\lambda-1}{\lambda}\right) \rho(1-\alpha) \\
+\gamma_{X} \Pi_{X 1 M 2}^{M 2}\left(\frac{\bar{P}_{X 1 M 2}}{\bar{P}_{X 1 M 2}-\bar{C}_{X 1 M 2}}-\frac{1}{\lambda} \frac{\bar{C}_{X 1 M 2}}{\bar{P}_{X 1 M 2}-\bar{C}_{X 1 M 2}}\right) \rho(1-\alpha)
\end{array}\right] \beta_{X 2 M 2} \\
& +\left[\frac{(1-\rho) \bar{P}_{X 1 M 2}}{\rho \bar{Z}+(1-\rho) \bar{P}_{X 1 M 2}}+\gamma_{M}\left(\Pi_{X 1 M 2}^{X 1} \frac{\bar{P}_{X 1 M 2}}{\bar{Z}-\bar{P}_{X 1 M 2}}+\Pi_{X 1 M 2}^{X 2} \frac{\bar{P}_{X 2 M 2}}{\bar{Z}-\bar{P}_{M 2 M 2}}\right)\right] \\
& +\left[\gamma_{M}\left(\Pi_{X 1 M 2}^{X 1} \frac{\bar{Z}}{\bar{Z}-\bar{P}_{X 1 M 2}}+\Pi_{X 2 M 2}^{X 2} \frac{\bar{Z}}{\bar{Z}-\bar{P}_{X 2 M 2}}\right)-\frac{\rho \bar{Z}}{\rho \bar{Z}+(1-\rho) \bar{P}_{X 1 M 2}}\right] \frac{E \hat{z} \hat{s}}{E \hat{s}^{2}} \\
& +\left[\begin{array}{c}
\gamma_{M}-\frac{\rho \overline{M C}_{X 1 M 2}}{(1-\rho) \bar{P}_{X 1 M 2}+\rho \overline{M C} \bar{C}_{X 1 M 2}} \frac{\lambda-1}{\lambda} \\
-\gamma_{X} \Pi_{X 1 M 1}^{M 1}\left(\frac{\bar{P}_{X 1 M 1}}{\bar{P}_{X 1 M 1}-\bar{C}_{X 1 M 1}}-\frac{1}{\lambda} \frac{\bar{C}_{X 1 M 1}}{\bar{P}_{X 1 M 1}-\bar{C}_{X 1 M 1}}\right) \\
-\gamma_{X} \Pi_{X 1 M 2}^{M 2}\left(\frac{\bar{P}_{X 1 M 2}}{\bar{P}_{X 1 M 2}-\bar{C}_{X 1 M 2}}-\frac{1}{\lambda} \frac{\bar{C}_{X 1 M 2}}{\bar{P}_{X 1 M 2}-\bar{C}_{X 1 M 2}}\right)
\end{array}\right] \frac{E \hat{q}^{s e t} \hat{s}}{E \hat{s}^{2}} \\
& +\left[\begin{array}{c}
\frac{\rho \overline{M C}_{X 1 M 2}}{(1-\rho) \bar{P}_{X 1 M 2}+\rho \overline{M C}_{X 1 M 2}}+\gamma_{X} \Pi_{X 1 M 1}^{M 1} \frac{\bar{C}_{X 1 M 1}}{\bar{P}_{X 1 B 1}-\bar{C}_{X 1 M 1}} \\
+\gamma_{X} \Pi_{X 1 M 2}^{M 2}{\overline{\bar{P}_{X 1 B 2}}}_{\bar{C}_{X 1 M 2}} \bar{C}_{X 1 M 2}
\end{array}\right]\left(\frac{E \hat{w} \hat{s}}{E \hat{s}^{2}}+\zeta\right)
\end{aligned}
$$

The other three relations are given in a separate detailed technical appendix. 


\section{References}

[1] Auer, Raphael, and Raphael Schoenle, 2012. "Market structure and exchange rate pass through," Swiss National Bank working paper 2012-14.

[2] Bacchetta, Philippe, and Eric van Wincoop, 2005. "A theory of the currency denomination of international trade." Journal of International Economics, 67 (2), pp. 295-319.

[3] Berman, Nicolas, Philippe Martin, and Thierry Mayer, 2012. "How do different exporters react to exchange rate changes?" Quarterly Journal of Economics, 127 (1), pp. 437-492.

[4] Camera, Gabriele, and Cemil Selcuk, 2009. "Price dispersion with directed search", Journal of the European Economic Association 7(6), pp. 1193-1224.

[5] Chipty, Tasneem, and Christopher Snyder, 1999. "The role of firm size in a bilateral bargaining: a study of the cable television industry", Review of Economics and Statistics 81(2), pp. 326-340.

[6] DeGraba, Patrick, 2005. "Quantity discounts from risk averse sellers", FTC working paper 276 .

[7] DeBlas, Beatriz and Katheryn Niles Russ, 2010. "Understanding markups in the open economy under Bertrand competition", NBER working paper 16587.

[8] Devereux, Michael, Charles Engel, and Peter Storgaard, 2004. "Endogenous exchange rate pass-through when nominal prices are set in advance." Journal of International Economics, 63 (2), pp. 263-291.

[9] Devereux, Michael, and Shouyong Shi, 2013. "Vehicle currency", International Economic Review, forthcoming.

[10] Dowbson, Paul, and Michael Waterson, 1997. "Countervailing power and consumer prices", The Economic Journal 107 (441), pp. 418-430.

[11] Engel, Charles, 2006. "Equivalence results for optimal pass-through, optimal indexing to exchange rates, and optimal choice of currency for export pricing," Journal of the European Economic Association, vol. 4 (6), pp. 1249-1260. 
[12] Friberg, Richard. 1998. "In which Currency Should Exporters Set their Prices?" Journal of International Economics, 45(1), pp. 59-76.

[13] Friberg, Richard, and Fredrik Wilander, 2008. "The currency denomination of exports - Aquestionnaire study", Journal of International Economics, 75(1), pp. 54-69.

[14] Garetto, Stefania, 2012. "Firms' heterogeneity and incomplete pass through," manuscript Boston University.

[15] Goldberg, Linda, and Cédric Tille, 2011. "Micro, Macro, and Strategic Forces in International Trade Invoicing", Federal Reserve Bank of New York staff report 405 .

[16] Goldberg, Linda, and Cédric Tille, 2008. "Vehicle currency use in international trade", Journal of International Economics, 76, pp. 177-192.

[17] Gopinath, Gita, Oleg Itskhoki, and Roberto Rigobon 2010. "Currency Choice and Exchange Rate Pass-Through", American Economic Review, 100 (1), pp. 304-336.

[18] Hellerstein, Rebecca, 2008. "Who bears the cost of a change in the exchange rate? Pass-through accounting for the case of beer," Journal of international economics, 76 (1), pp.14-32

[19] Horn, Henrick, and Asher Wolinsky, 1988. "Bilateral monopolies and incentives for mergers", Rand Journal of Economics 19 (3), pp. 408-419.

[20] Inderst, Roman, and Christian Wey, 2003. "Bargaining, mergers and technology choice in bilaterally oligopolistic industries", Rand Journal of Economics, 34 (1), pp. 1-19.

[21] Ito, Takatoshi, Satoshi Koibuchi, Kiyotaka Sato and Junko Shimizu, 2012. "The choice of an invoicing currency by globally operating firms: A firm-level analysis of Japanese exporters' invoicing behavior", International Journal of Finance and Economics, 17 (4), pp. 305-320.

[22] Normann, Hans-Theo, Bradley Ruffle, and Christopher Snyder, 2007. "Do buyer-size discounts depend on the curvature of the surplus function? Exper- 
imental tests of bargaining models", Rand Journal of Economics 38 (3), pp. $747-767$.

[23] Novy, Dennis, 2006. "Hedge your Costs: Exchange Rate Risk and Endogenous Currency Invoicing", Warwick economic research paper 765.

[24] Selcuk, Cemil, 2012. "Trading mechanism selection with directed search when buyers are risk averse", Economics Letters, 115 (2), pp. 207-210.

[25] Tille, Cédric, and Eric van Wincoop, 2010. "International Capital Flows.", Journal of International Economics, vol. 80, pp. 157-175. 
Figure 1: Pricing and invoicing, fragmentation case
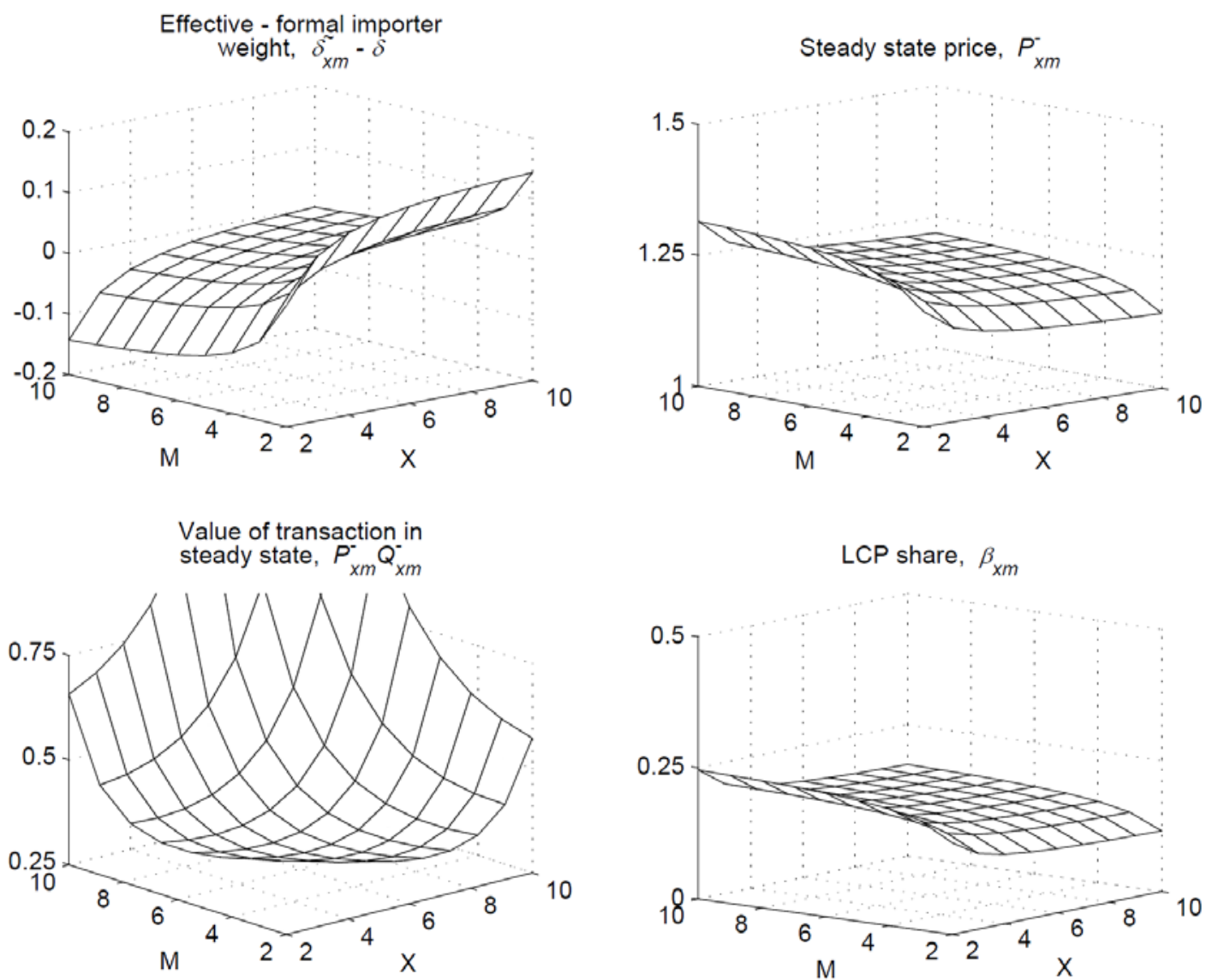

$\mathrm{M}$ denotes the number of (identical) importers. The higher $\mathrm{M}$ the more fragmented are importers across many small ones. $\mathrm{X}$ denotes the number of (identical) exporters. The higher $\mathrm{X}$ the more fragmented are exporters across many small ones.

Parameters:

$\delta=0.5, \gamma_{X}=2, \gamma_{M}=2, \rho=2, \lambda=1, W_{x}=1, Q^{\text {set }}=10, \zeta_{x}=0, E\left(q^{\text {set }} s\right) /\left(E s^{2}\right)=0, E\left(w_{x} s\right) /\left(E s^{2}\right)=0, E(z$ $s) /\left(E s^{2}\right)=0$. 
Figure 2: Role of formal bargaining weight, fragmentation case
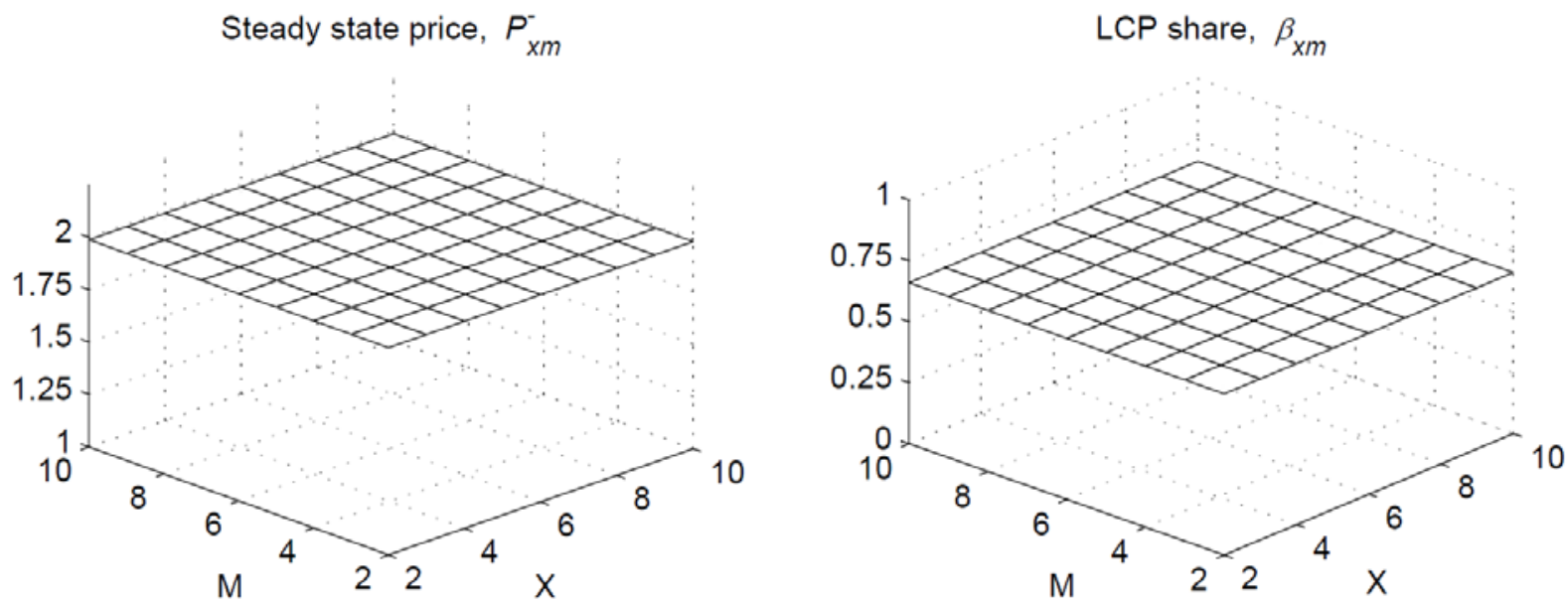

$\mathrm{M}$ denotes the number of (identical) importers. The higher $\mathrm{M}$ the more fragmented are importers across many small ones. $\mathrm{X}$ denotes the number of (identical) exporters. The higher $\mathrm{X}$ the more fragmented are exporters across many small ones.

Parameters are as in the baseline of Figure 2, except for $\delta=0$ instead of $\delta=0.5$.

\section{Figure 3: Role of overall risk aversion, fragmentation case}
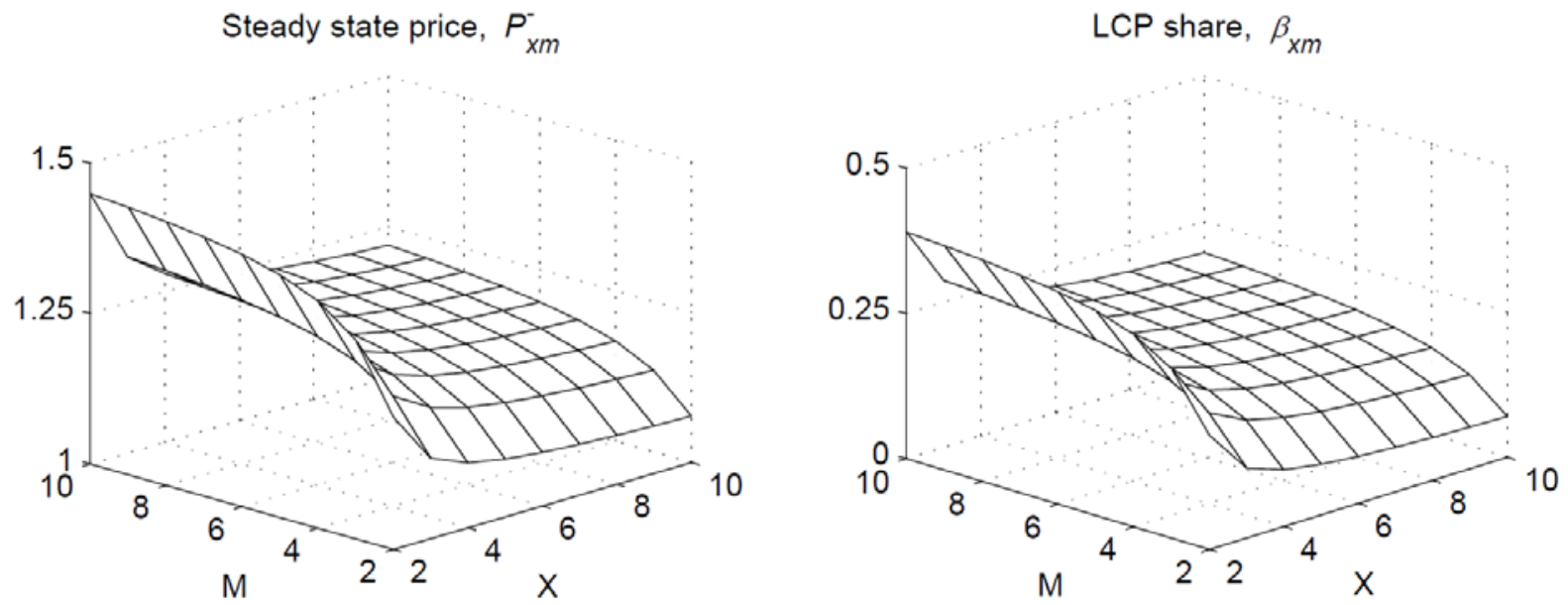

$\mathrm{M}$ denotes the number of (identical) importers. The higher $\mathrm{M}$ the more fragmented are importers across many small ones. $\mathrm{X}$ denotes the number of (identical) exporters. The higher $\mathrm{X}$ the more fragmented are exporters across many small ones.

Parameters are as in the baseline of Figure 2, except for $\gamma_{X}=4, \gamma_{M}=4$ instead of $\gamma_{X}=2, \gamma_{M}=2$. 
Figure 4: Role of importer's risk aversion, fragmentation case
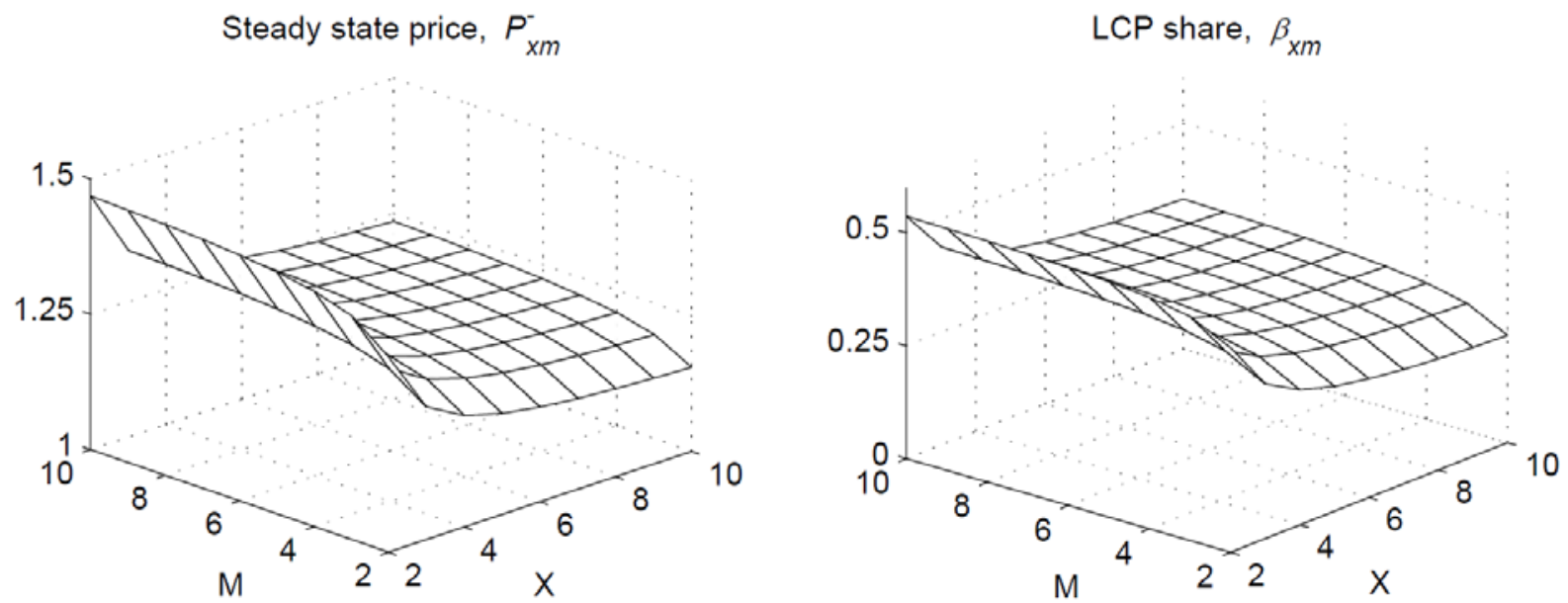

$\mathrm{M}$ denotes the number of (identical) importers. The higher $\mathrm{M}$ the more fragmented are importers across many small ones. $\mathrm{X}$ denotes the number of (identical) exporters. The higher $\mathrm{X}$ the more fragmented are exporters across many small ones.

Parameters are as in the baseline of Figure 2, except for $\gamma_{M}=4$ instead of $\gamma_{M}=2$.

\section{Figure 5: Role of price sensitivity, fragmentation case}


$\mathrm{M}$ denotes the number of (identical) importers. The higher $\mathrm{M}$ the more fragmented are importers across many small ones. $\mathrm{X}$ denotes the number of (identical) exporters. The higher $\mathrm{X}$ the more fragmented are exporters across many small ones.

Parameters are as in the baseline of Figure 2, except for $\rho=5$ instead of $\rho=2$. 
Figure 6: Role of returns to scale, fragmentation case
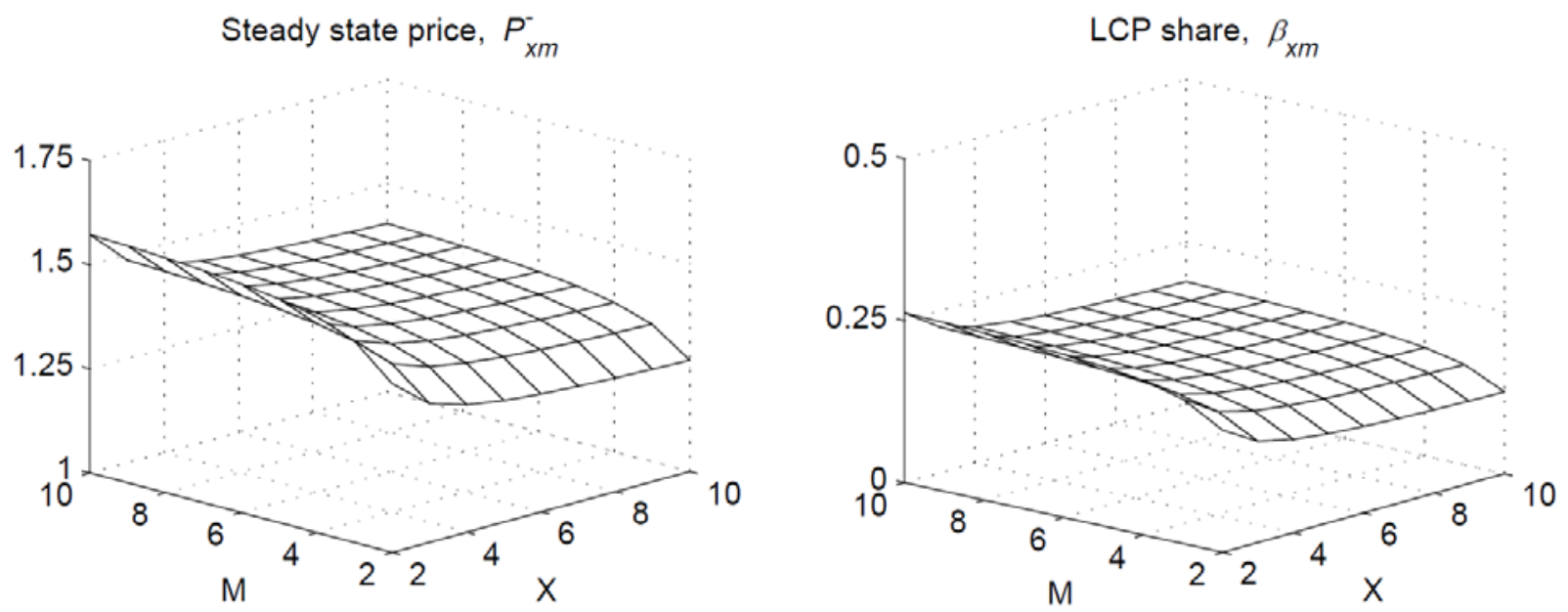

$\mathrm{M}$ denotes the number of (identical) importers. The higher $\mathrm{M}$ the more fragmented are importers across many small ones. $\mathrm{X}$ denotes the number of (identical) exporters. The higher $\mathrm{X}$ the more fragmented are exporters across many small ones.

Parameters are as in the baseline of Figure 2, except for $\lambda=0.75$ instead of $\lambda=1$.

Figure 7: Role of link between cost and exchange rate, fragmentation case
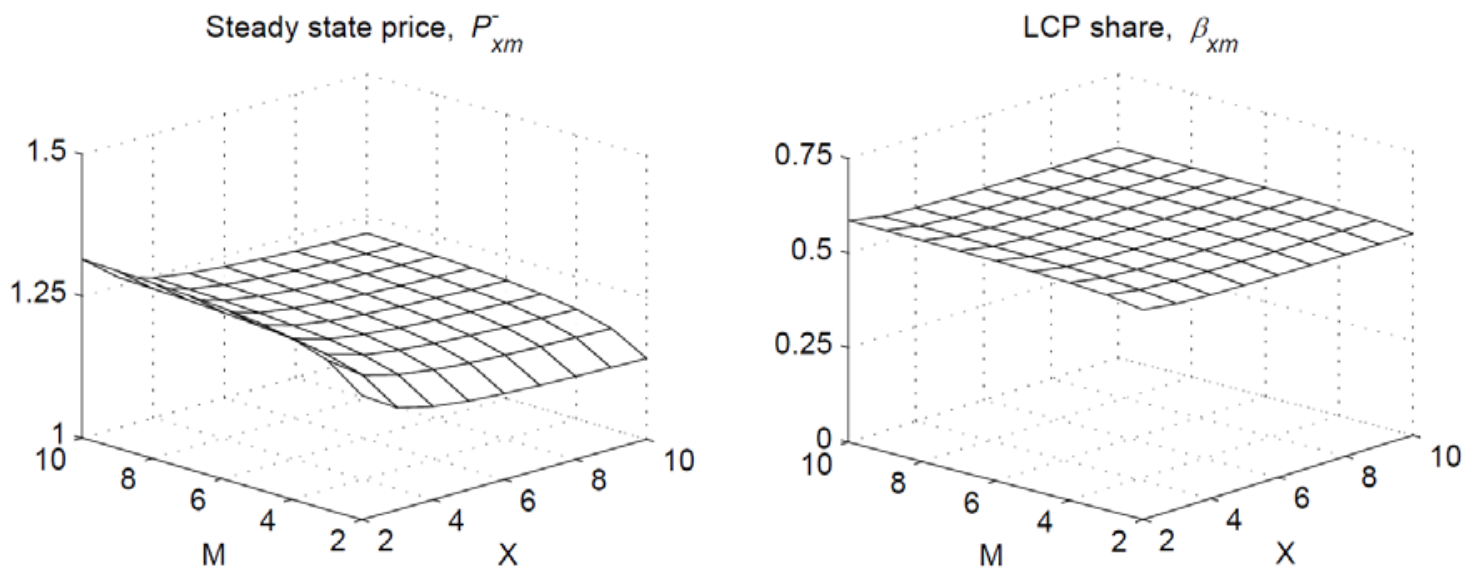

$\mathrm{M}$ denotes the number of (identical) importers. The higher $\mathrm{M}$ the more fragmented are importers across many small ones. $\mathrm{X}$ denotes the number of (identical) exporters. The higher $\mathrm{X}$ the more fragmented are exporters across many small ones.

Parameters are as in the baseline of Figure 2, except for $\zeta_{x}=0.5$ instead of $\zeta_{x}=0$. 
Figure 8: Effective bargaining weight of importer (relative to formal weight) $\tilde{\delta}_{x m}-\delta$, heterogeneity case
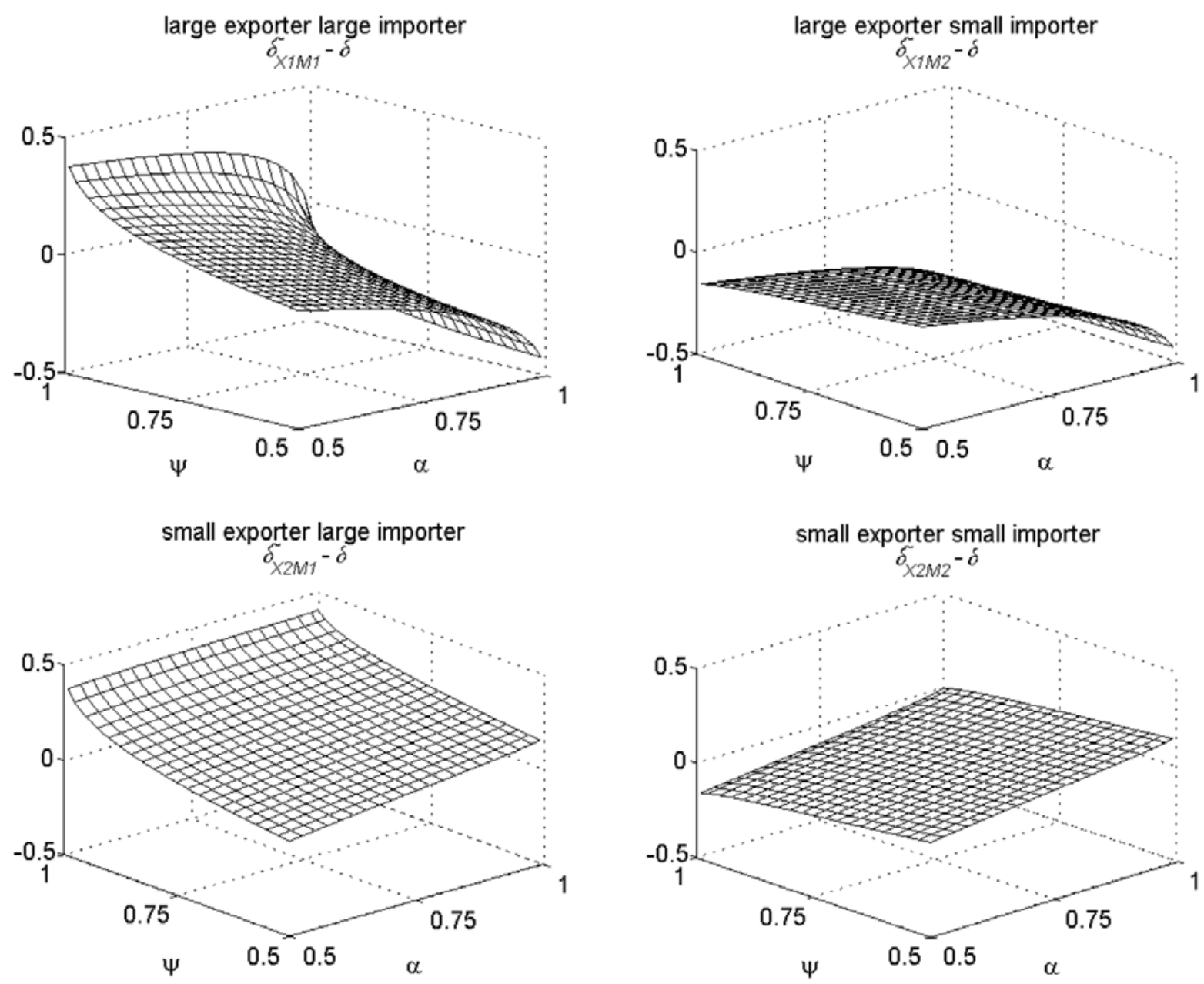

$\alpha$ denotes the size of the larger exporter. The higher $\alpha$ the more heterogeneous are exporters between a large exporter and a small one

$\psi$ denotes the size of the larger importer. The higher $\psi$ the more heterogeneous are importers between a large importer and a small one

Parameters:

$\delta=0.5, \gamma_{X}=2, \gamma_{M}=2, \rho=2, \lambda=1, W_{X}=1, Q^{\text {set }}=10, \zeta_{X}=0, E\left(q^{\text {set }} s\right) /\left(E s^{2}\right)=0, E\left(w_{X} s\right) /\left(E s^{2}\right)=0, E(z$ $s) /\left(E s^{2}\right)=0$. 
Figure 9: Steady state price $\bar{P}_{x m}$, heterogeneity case
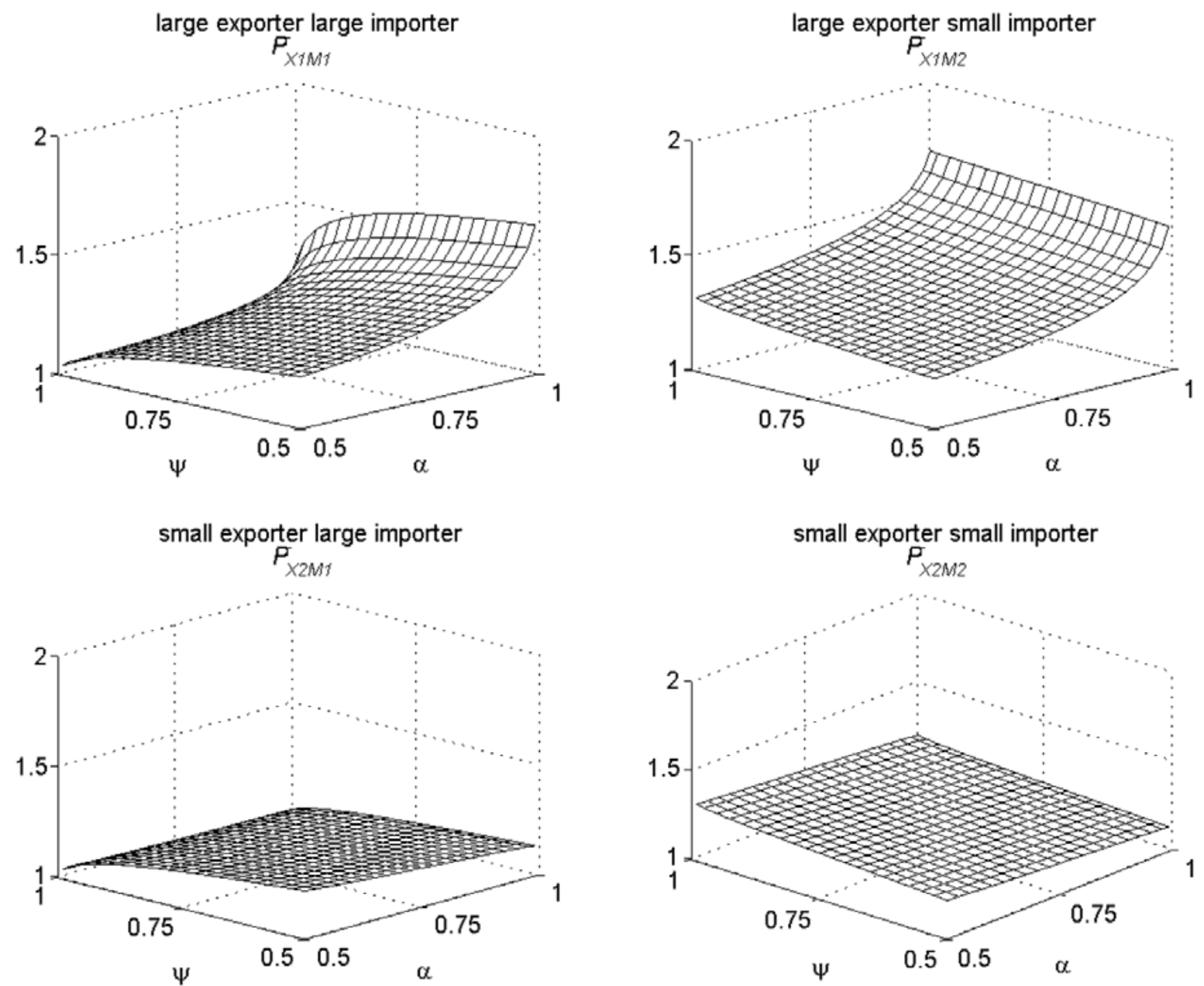

$\alpha$ denotes the size of the larger exporter. The higher $\alpha$ the more heterogeneous are exporters between a large exporter and a small one $\psi$ denotes the size of the larger importer. The higher $\psi$ the more heterogeneous are importers between a large importer and a small one

Parameters:

$\delta=0.5, \gamma_{X}=2, \gamma_{M}=2, \rho=2, \lambda=1, W_{x}=1, Q^{\text {set }}=10, \zeta_{X}=0, E\left(q^{\text {set }} s\right) /\left(E s^{2}\right)=0, E\left(w_{x} s\right) /\left(E s^{2}\right)=0, E(z$ $s) /\left(E s^{2}\right)=0$. 
Figure 10: LCP share $\beta_{x m}$, heterogeneity case
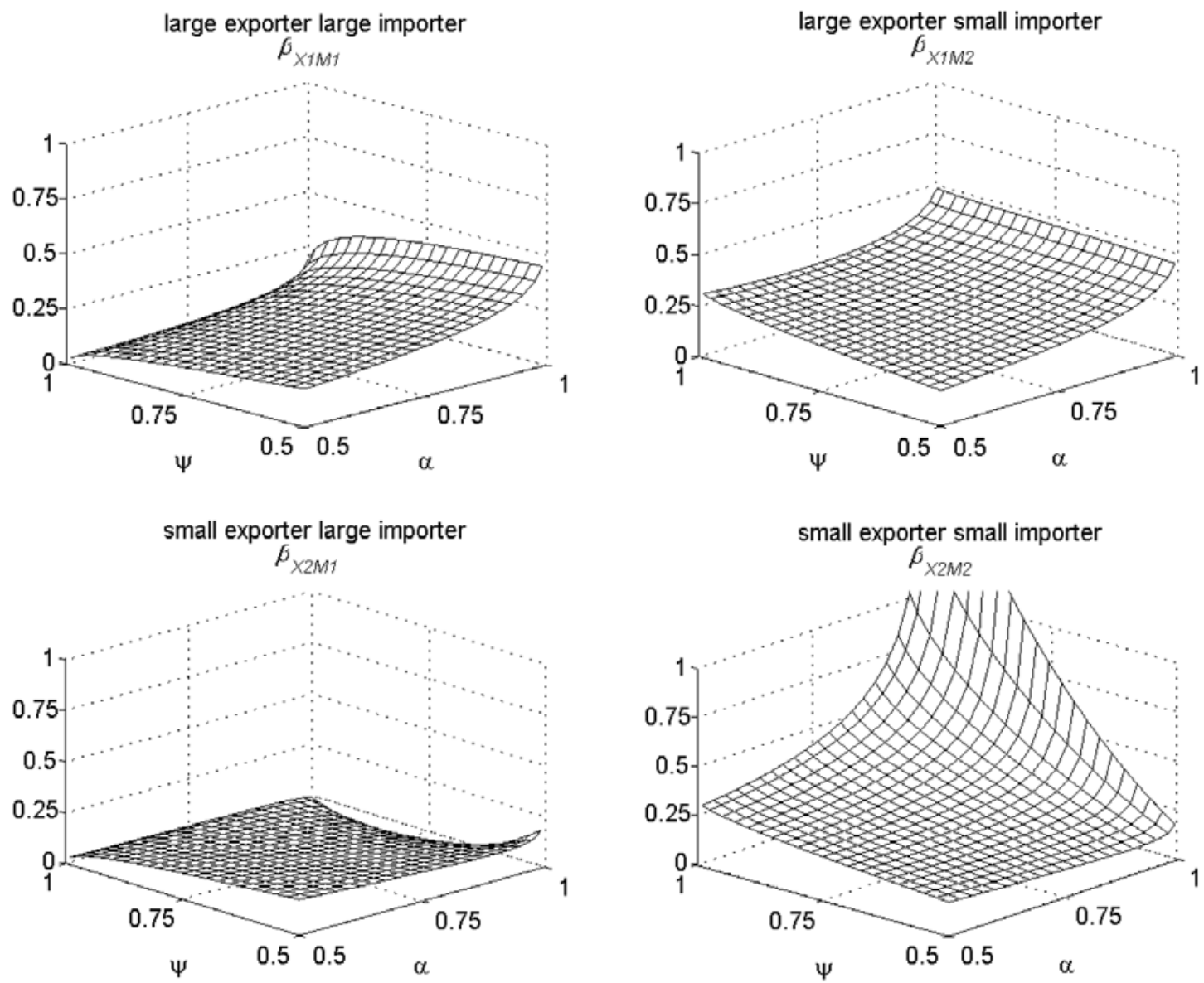

$\alpha$ denotes the size of the larger exporter. The higher $\alpha$ the more heterogeneous are exporters between a large exporter and a small one $\psi$ denotes the size of the larger importer. The higher $\psi$ the more heterogeneous are importers between a large importer and a small one

Parameters:

$\delta=0.5, \gamma_{X}=2, \gamma_{M}=2, \rho=2, \lambda=1, W_{X}=1, Q^{\text {set }}=10, \zeta_{X}=0, E\left(q^{\text {set }} s\right) /\left(E s^{2}\right)=0, E\left(w_{x} s\right) /\left(E s^{2}\right)=0, E(z$ $s) /\left(E s^{2}\right)=0$. 
Figure 11: Average and standard deviation of steady state price $\bar{P}_{x m}$ and LCP share $\beta_{x m}$, heterogeneity case
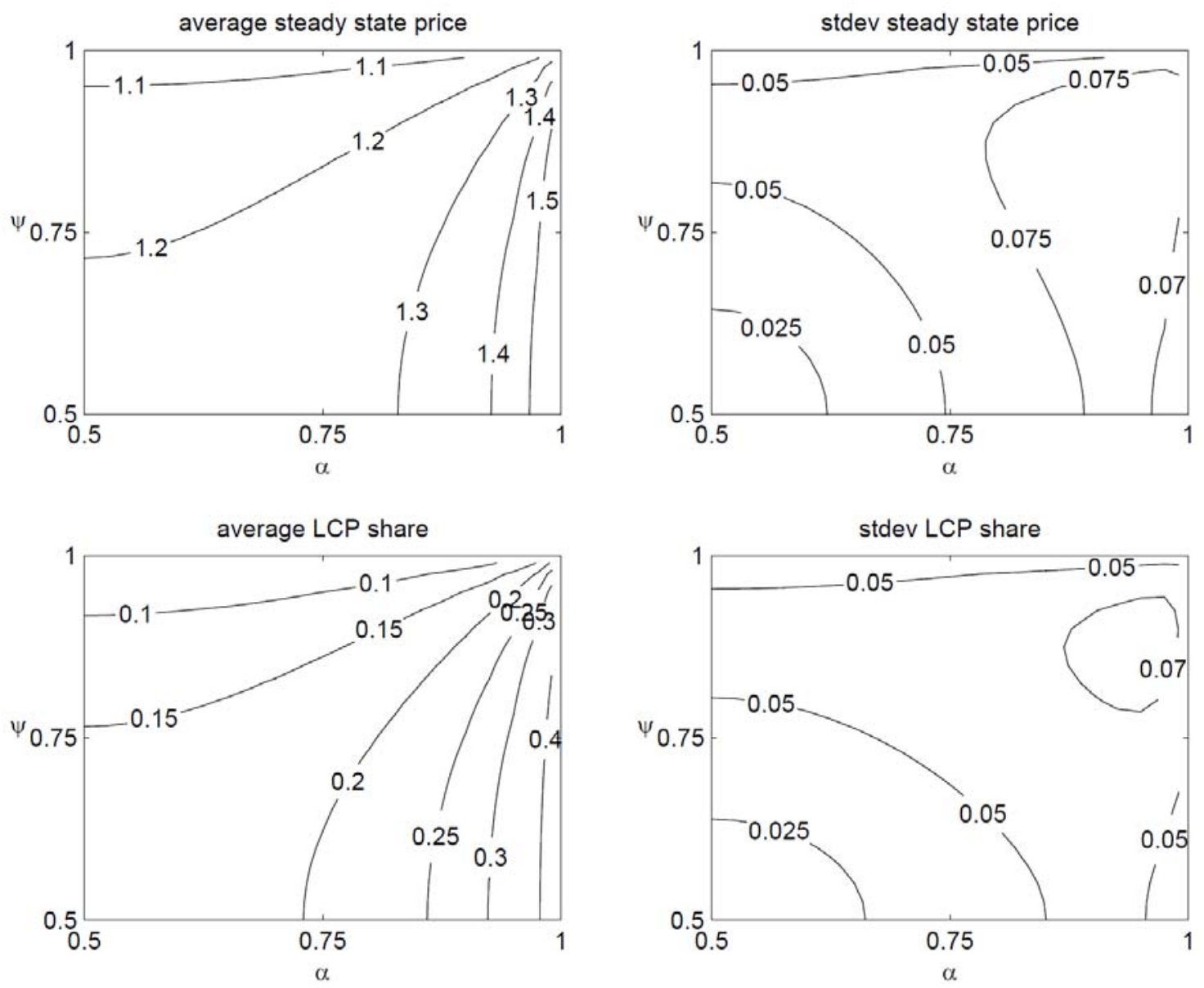

$\alpha$ denotes the size of the larger exporter. The higher $\alpha$ the more heterogeneous are exporters between a large exporter and a small one

$\psi$ denotes the size of the larger importer. The higher $\psi$ the more heterogeneous are importers between a large importer and a small one

Parameters:

$\delta=0.5, \gamma_{X}=2, \gamma_{M}=2, \rho=2, \lambda=1, W_{X}=1, Q^{\text {set }}=10, \zeta_{X}=0, E\left(q^{\text {set }} s\right) /\left(E s^{2}\right)=0, E\left(w_{X} s\right) /\left(E s^{2}\right)=0, E(z$ $s) /\left(E s^{2}\right)=0$. 
Figure 12: Correlation between transaction value $\bar{P}_{x m} \bar{Q}_{x m}$ and LCP share $\beta_{x m}$, heterogeneity case

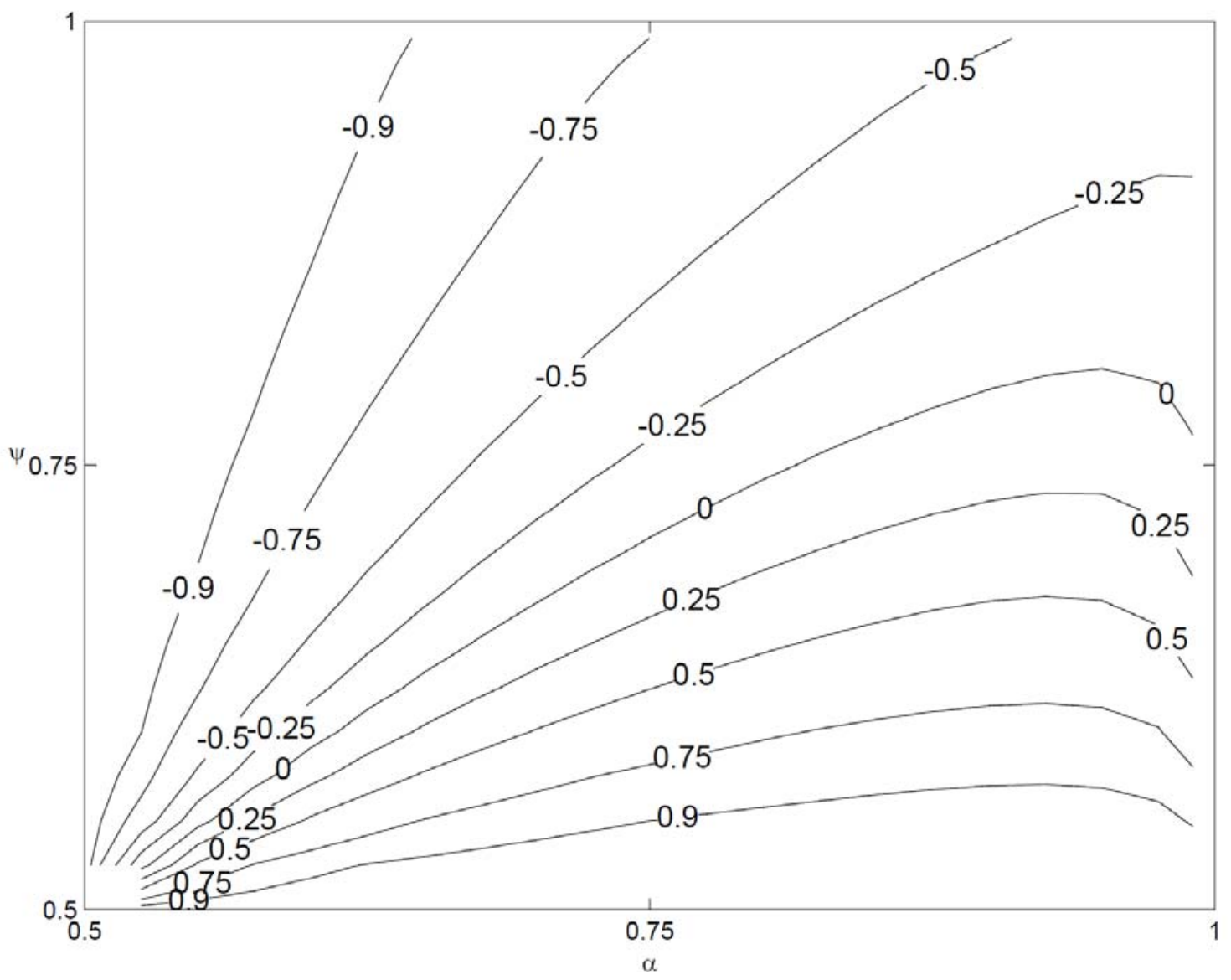

$\alpha$ denotes the size of the larger exporter. The higher $\alpha$ the more heterogeneous are exporters between a large exporter and a small one

$\psi$ denotes the size of the larger importer. The higher $\psi$ the more heterogeneous are importers between a large importer and a small one

Parameters:

$\delta=0.5, \gamma_{X}=2, \gamma_{M}=2, \rho=2, \lambda=1, W_{X}=1, Q^{\text {set }}=10, \zeta_{X}=0, E\left(q^{\text {set }} s\right) /\left(E s^{2}\right)=0, E\left(w_{X} s\right) /\left(E s^{2}\right)=0, E(z$ $s) /\left(E s^{2}\right)=0$. 
Figure 13: Role of overall risk aversion, Average and standard deviation of steady price $\bar{P}_{x m}$ and LCP share $\beta_{x m}$, heterogeneity case
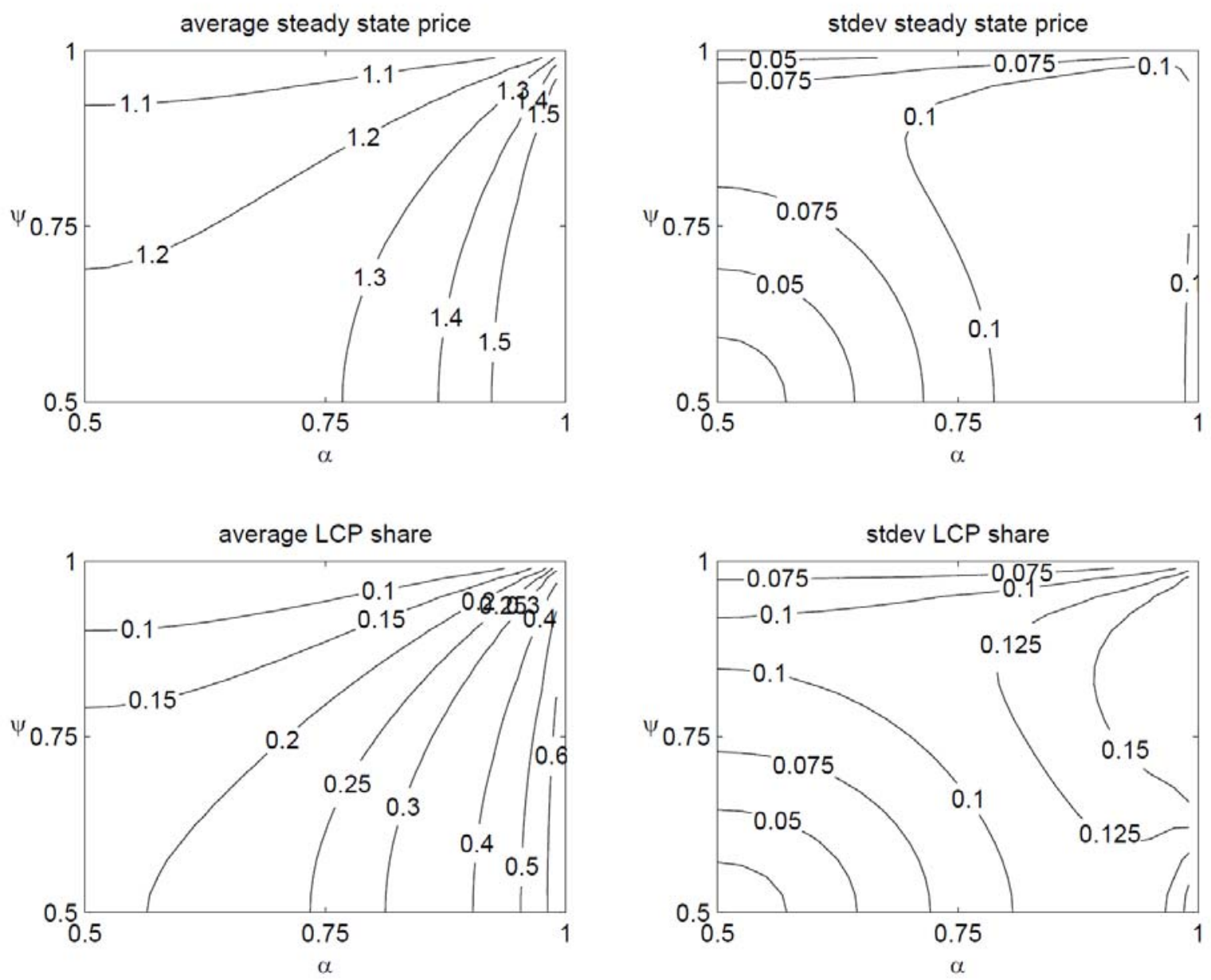

$\alpha$ denotes the size of the larger exporter. The higher $\alpha$ the more heterogeneous are exporters between a large exporter and a small one $\psi$ denotes the size of the larger importer. The higher $\psi$ the more heterogeneous are importers between a large importer and a small one

Parameters are as in the baseline of Figures 8-12, except for $\gamma_{X}=4, \gamma_{M}=4$ instead of $\gamma_{X}=2, \gamma_{M}=2$. 
Figure 14: Role of overall risk aversion, Correlation between transaction value $\bar{P}_{x m} \bar{Q}_{x m}$ and LCP share $\beta_{x m}$, heterogeneity case

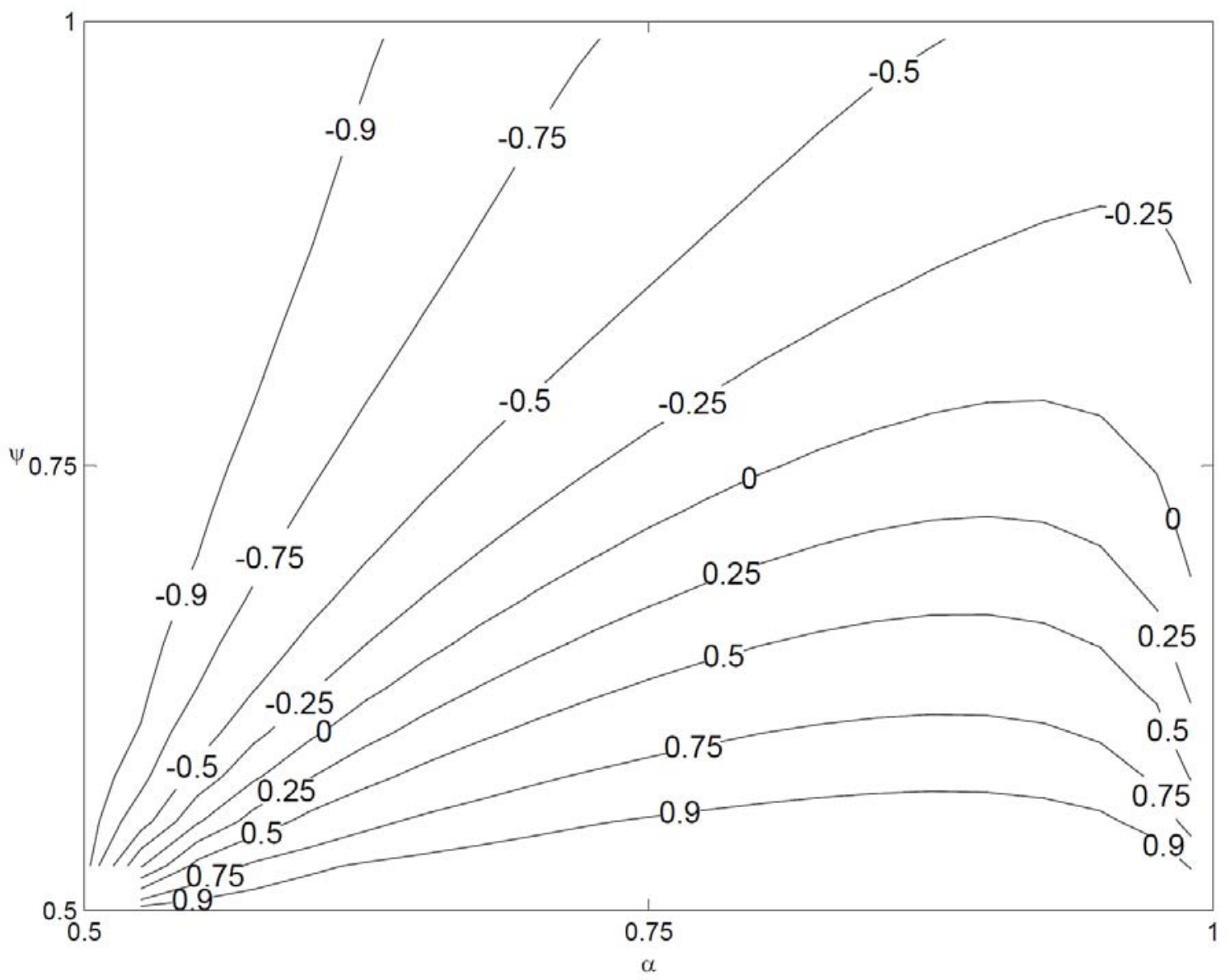

$\alpha$ denotes the size of the larger exporter. The higher $\alpha$ the more heterogeneous are exporters between a large exporter and a small one

$\psi$ denotes the size of the larger importer. The higher $\psi$ the more heterogeneous are importers between a large importer and a small one

Parameters are as in the baseline of Figures 8-12, except for $\gamma_{X}=4, \gamma_{M}=4$ instead of $\gamma_{X}=2, \gamma_{M}=2$. 
Figure 15: Role of importer's risk aversion, Average and standard deviation of steady state price $\bar{P}_{x m}$ and LCP share $\beta_{x m}$, heterogeneity case
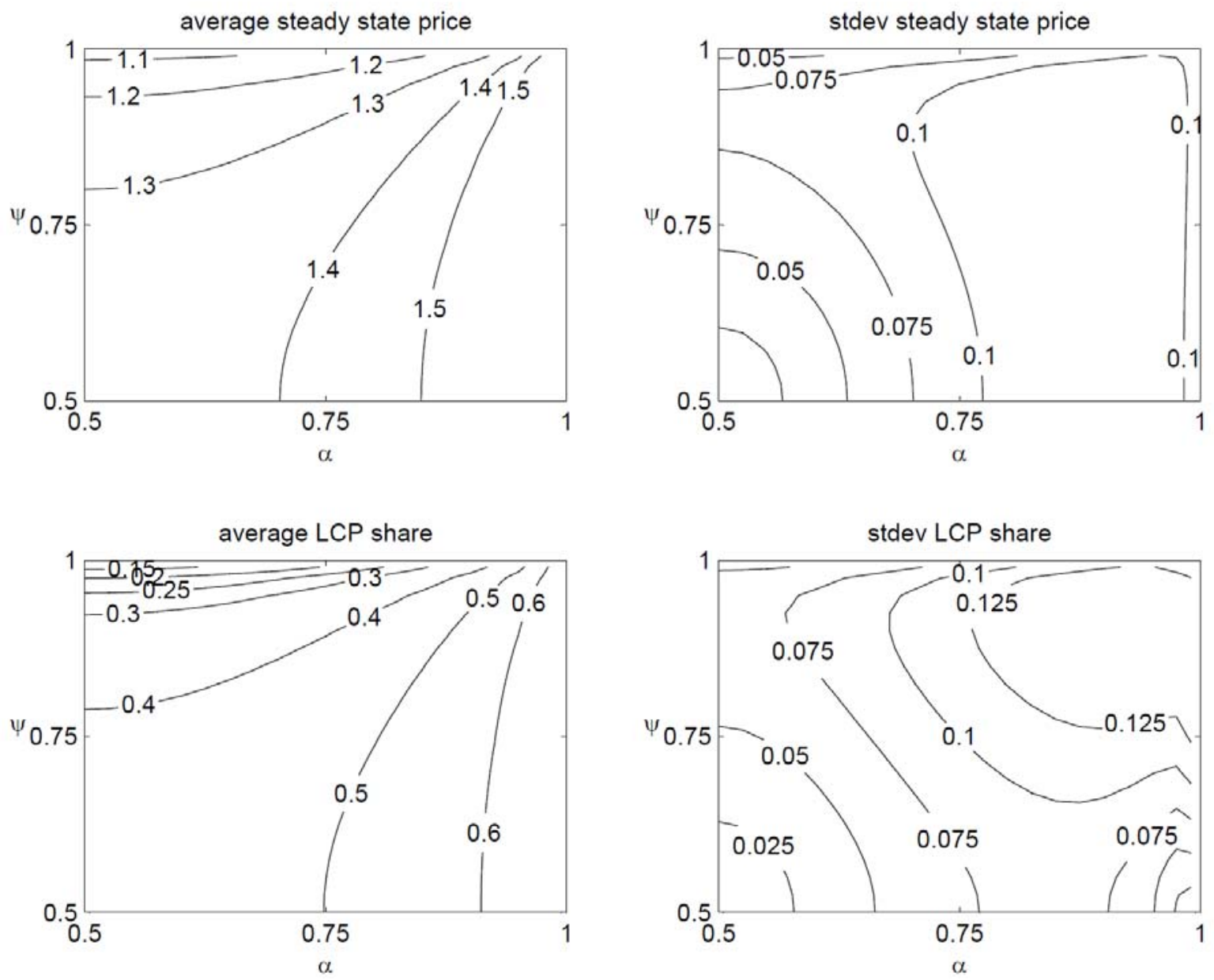

$\alpha$ denotes the size of the larger exporter. The higher $\alpha$ the more heterogeneous are exporters between a large exporter and a small one

$\psi$ denotes the size of the larger importer. The higher $\psi$ the more heterogeneous are importers between a large importer and a small one

Parameters are as in the baseline of Figures 8-12, except for $\gamma_{M}=4$ instead of $\gamma_{M}=2$. 
Figure 16: Role of importer's risk aversion, Correlation between transaction value $\bar{P}_{x m} \bar{Q}_{x m}$ and LCP share $\beta_{x m}$, heterogeneity case

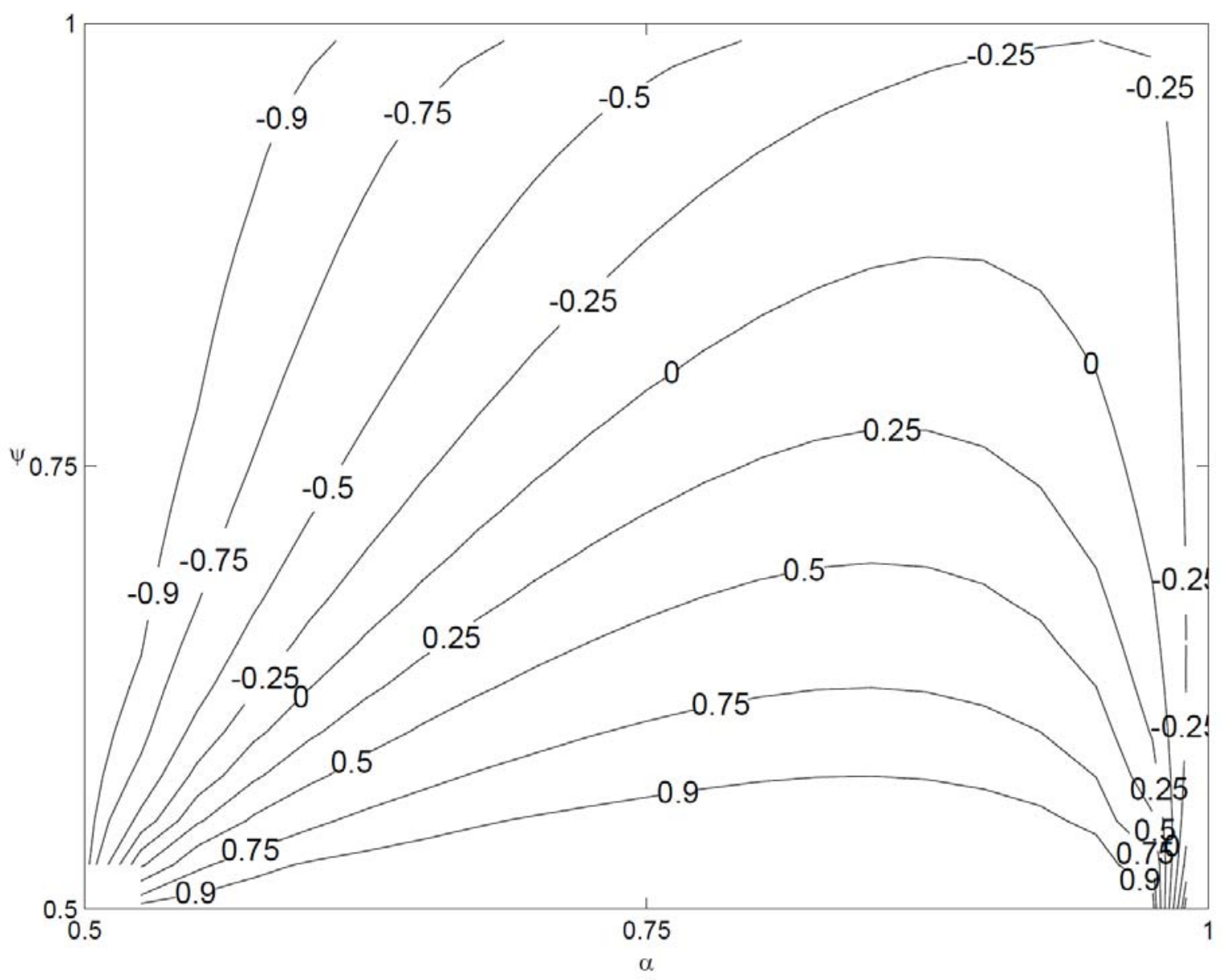

$\alpha$ denotes the size of the larger exporter. The higher $\alpha$ the more heterogeneous are exporters between a large exporter and a small one

$\psi$ denotes the size of the larger importer. The higher $\psi$ the more heterogeneous are importers between a large importer and a small one

Parameters are as in the baseline of Figures 8-12, except for $\gamma_{M}=4$ instead of $\gamma_{M}=2$. 
Figure 17: Role of price sensitivity, Average and standard deviation of steady state price $\bar{P}_{x m}$ and LCP share $\beta_{x m}$, heterogeneity case
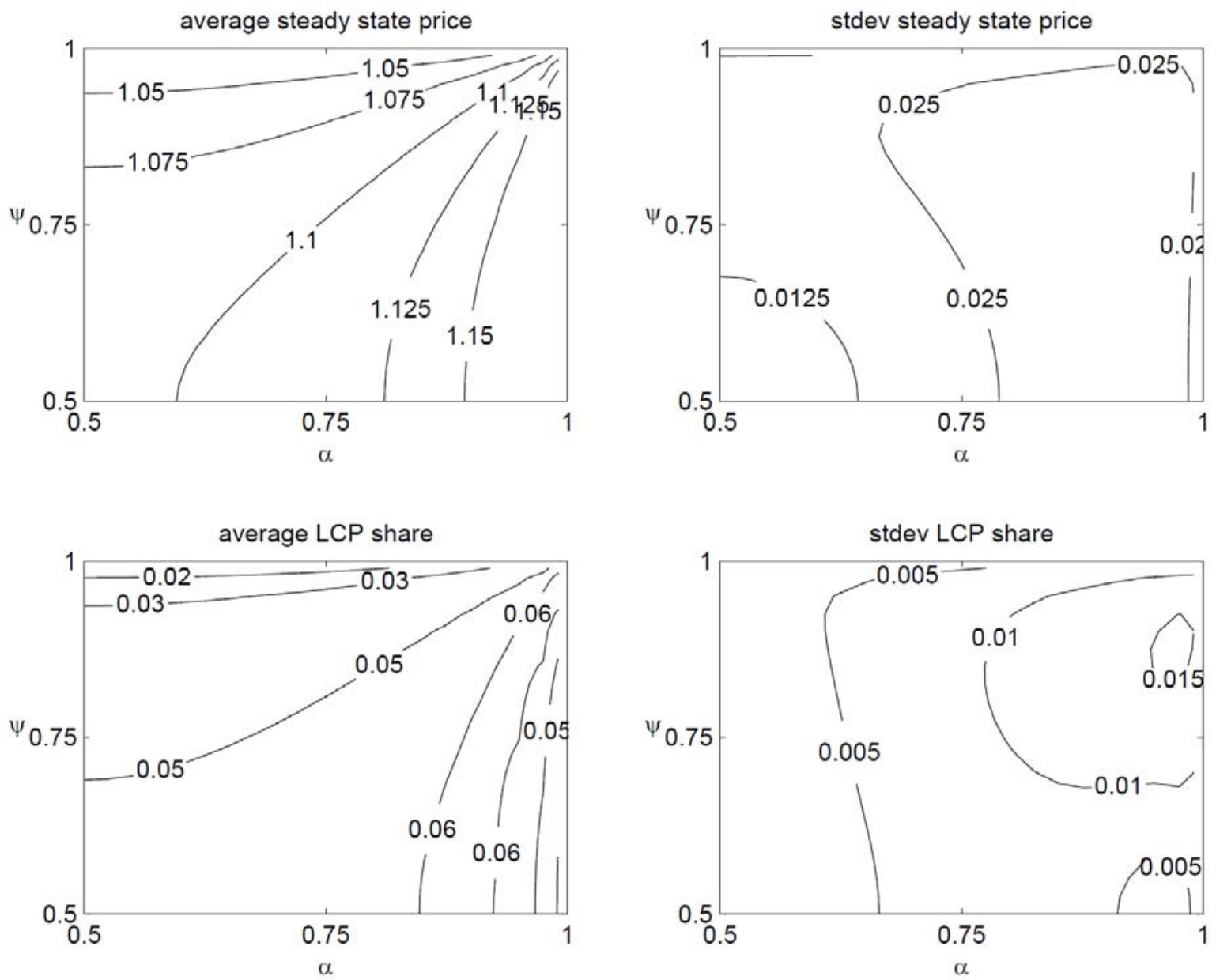

$\alpha$ denotes the size of the larger exporter. The higher $\alpha$ the more heterogeneous are exporters between a large exporter and a small one

$\psi$ denotes the size of the larger importer. The higher $\psi$ the more heterogeneous are importers between a large importer and a small one

Parameters are as in the baseline of Figures 8-12, except for $\rho=5$ instead of $\rho=2$. 
Figure 18: Role of price sensitivity, Correlation between transaction value $\bar{P}_{x m} \bar{Q}_{x m}$ and LCP share $\beta_{x m}$, heterogeneity case

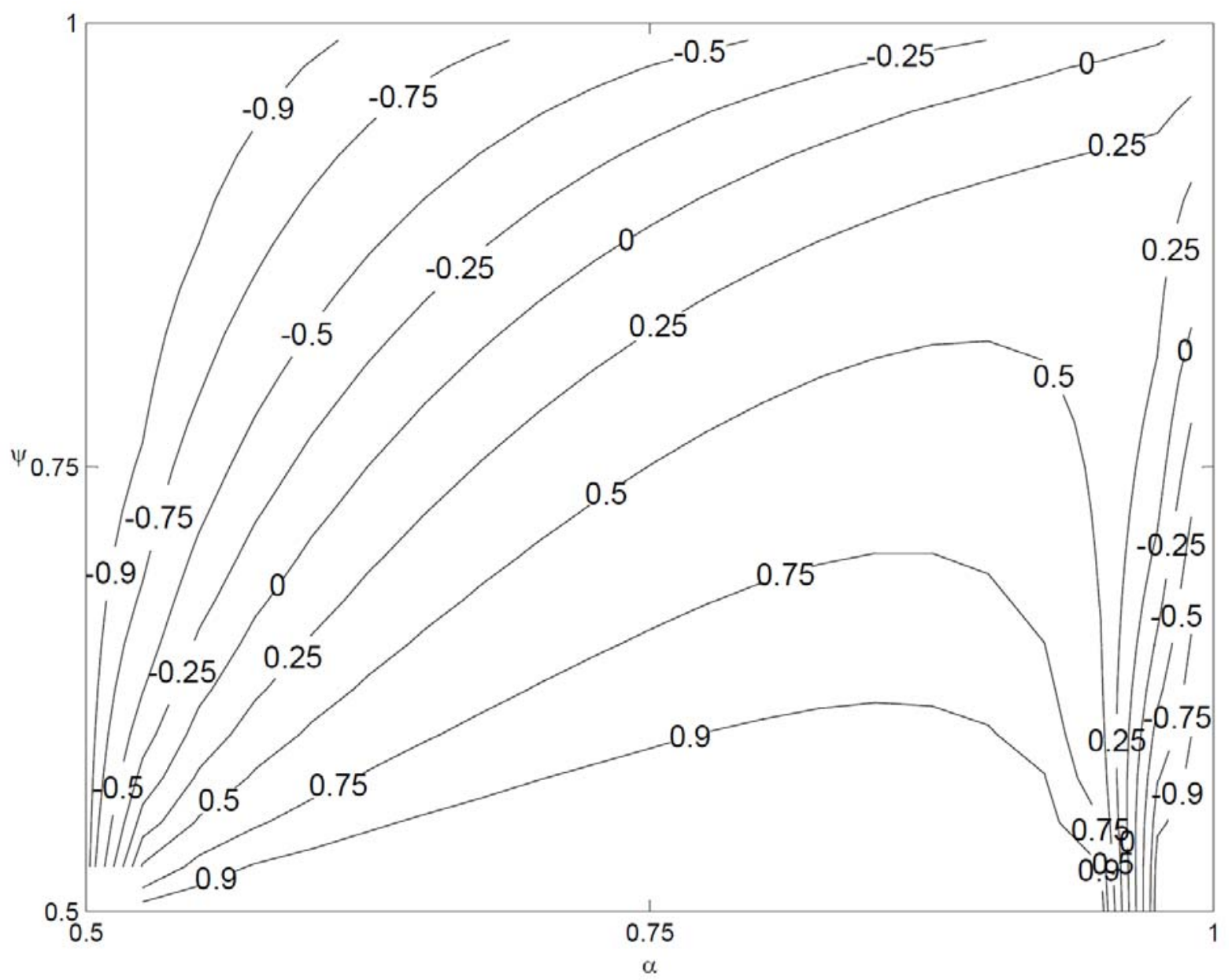

$\alpha$ denotes the size of the larger exporter. The higher $\alpha$ the more heterogeneous are exporters between a large exporter and a small one $\psi$ denotes the size of the larger importer. The higher $\psi$ the more heterogeneous are importers between a large importer and a small one

Parameters are as in the baseline of Figures 8-12, except for $\rho=5$ instead of $\rho=2$. 
Figure 19: Role of returns to scale, Average and standard deviation of steady state price $\bar{P}_{x m}$ and LCP share $\beta_{x m}$, heterogeneity case
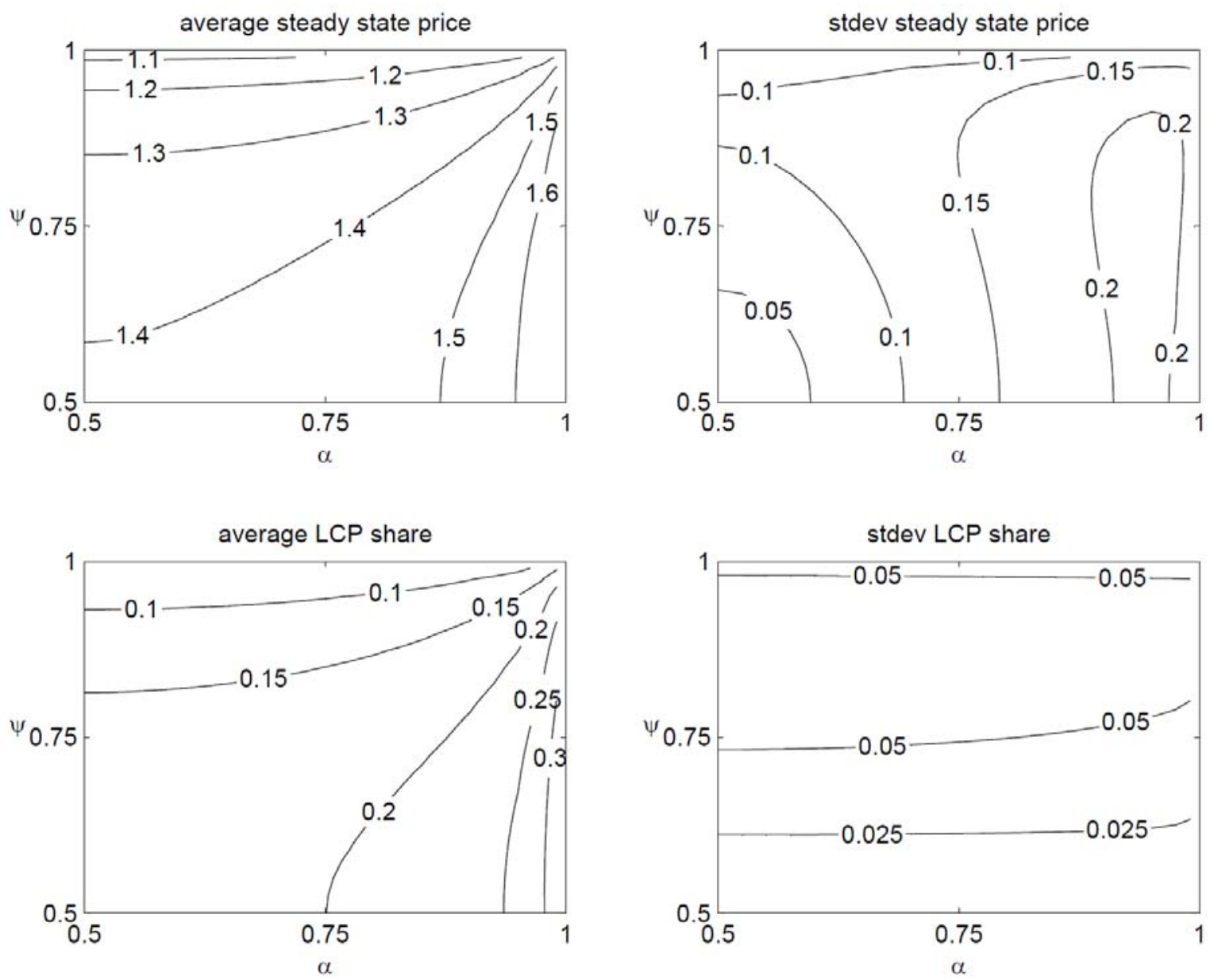

$\alpha$ denotes the size of the larger exporter. The higher $\alpha$ the more heterogeneous are exporters between a large exporter and a small one

$\psi$ denotes the size of the larger importer. The higher $\psi$ the more heterogeneous are importers between a large importer and a small one

Parameters are as in the baseline of Figures 8-12, except for $\lambda=0.75$ instead of $\lambda=1$. 
Figure 20: Role of returns to scale, Correlation between transaction value $\bar{P}_{x m} \bar{Q}_{x m}$ and LCP share $\beta_{x m}$, heterogeneity case

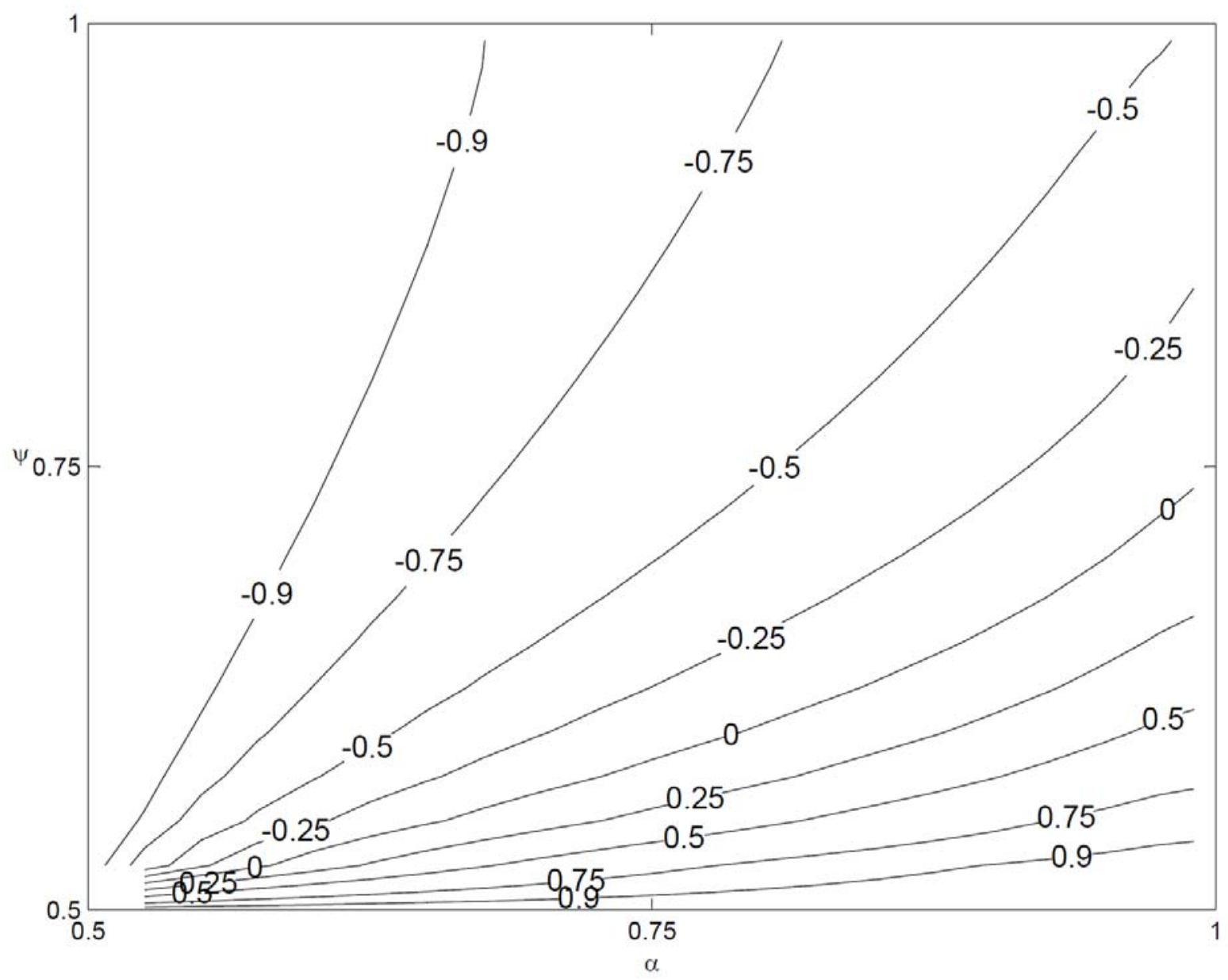

$\alpha$ denotes the size of the larger exporter. The higher $\alpha$ the more heterogeneous are exporters between a large exporter and a small one

$\psi$ denotes the size of the larger importer. The higher $\psi$ the more heterogeneous are importers between a large importer and a small one

Parameters are as in the baseline of Figures 8-12, except for $\lambda=0.75$ instead of $\lambda=1$. 
Figure 21: Role of link between cost and exchange rate, Average and standard deviation of steady state price $\bar{P}_{x m}$ and LCP share $\beta_{x m}$, heterogeneity case
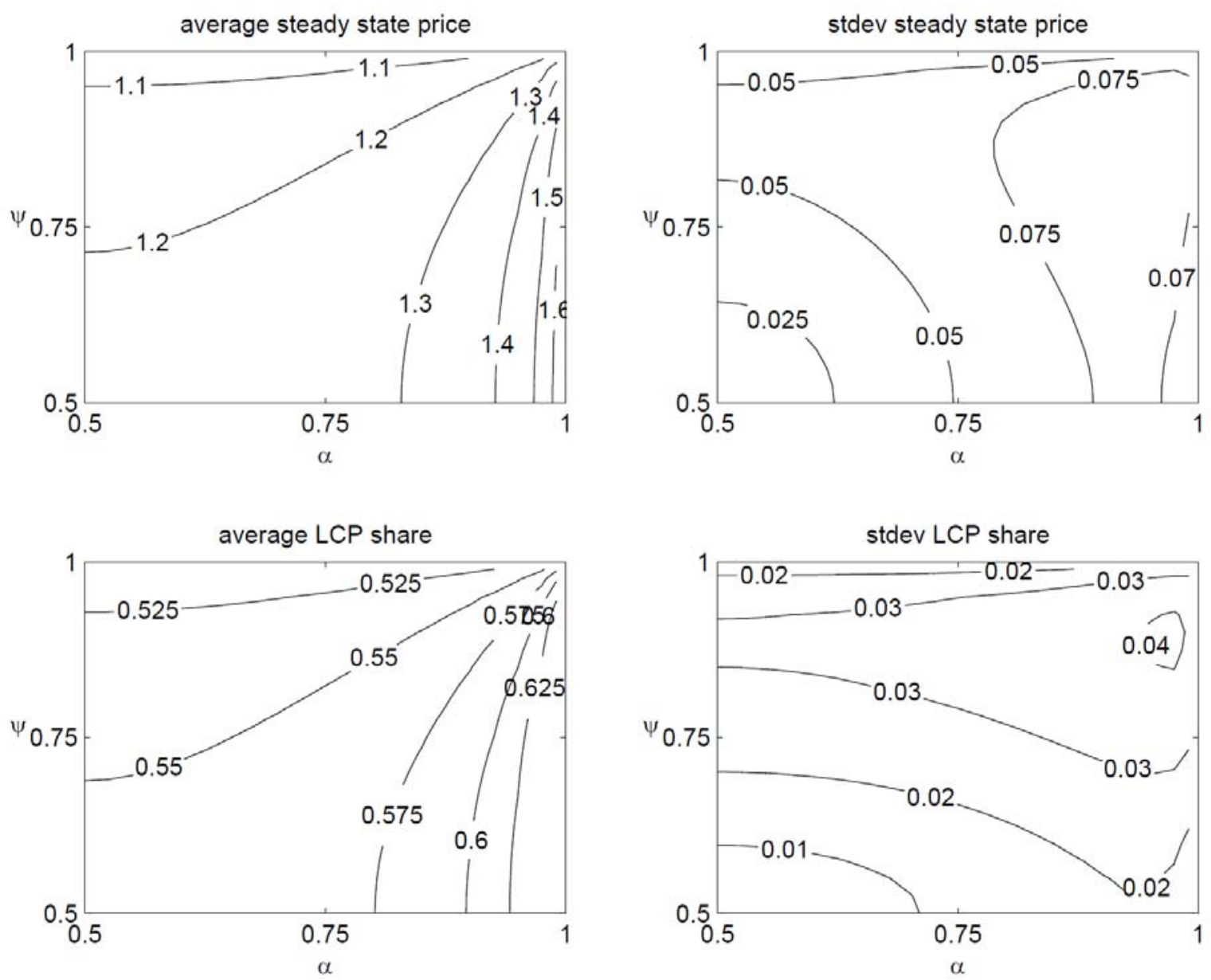

$\alpha$ denotes the size of the larger exporter. The higher $\alpha$ the more heterogeneous are exporters between a large exporter and a small one

$\psi$ denotes the size of the larger importer. The higher $\psi$ the more heterogeneous are importers between a large importer and a small one

Parameters are as in the baseline of Figures 8-12, except for $\zeta_{x}=0.5$ instead of $\zeta_{x}=0$. 
Figure 22: Role of link between cost and exchange rate, Correlation between transaction value $\bar{P}_{x m} \bar{Q}_{x m}$ and LCP share $\beta_{x m}$, heterogeneity case

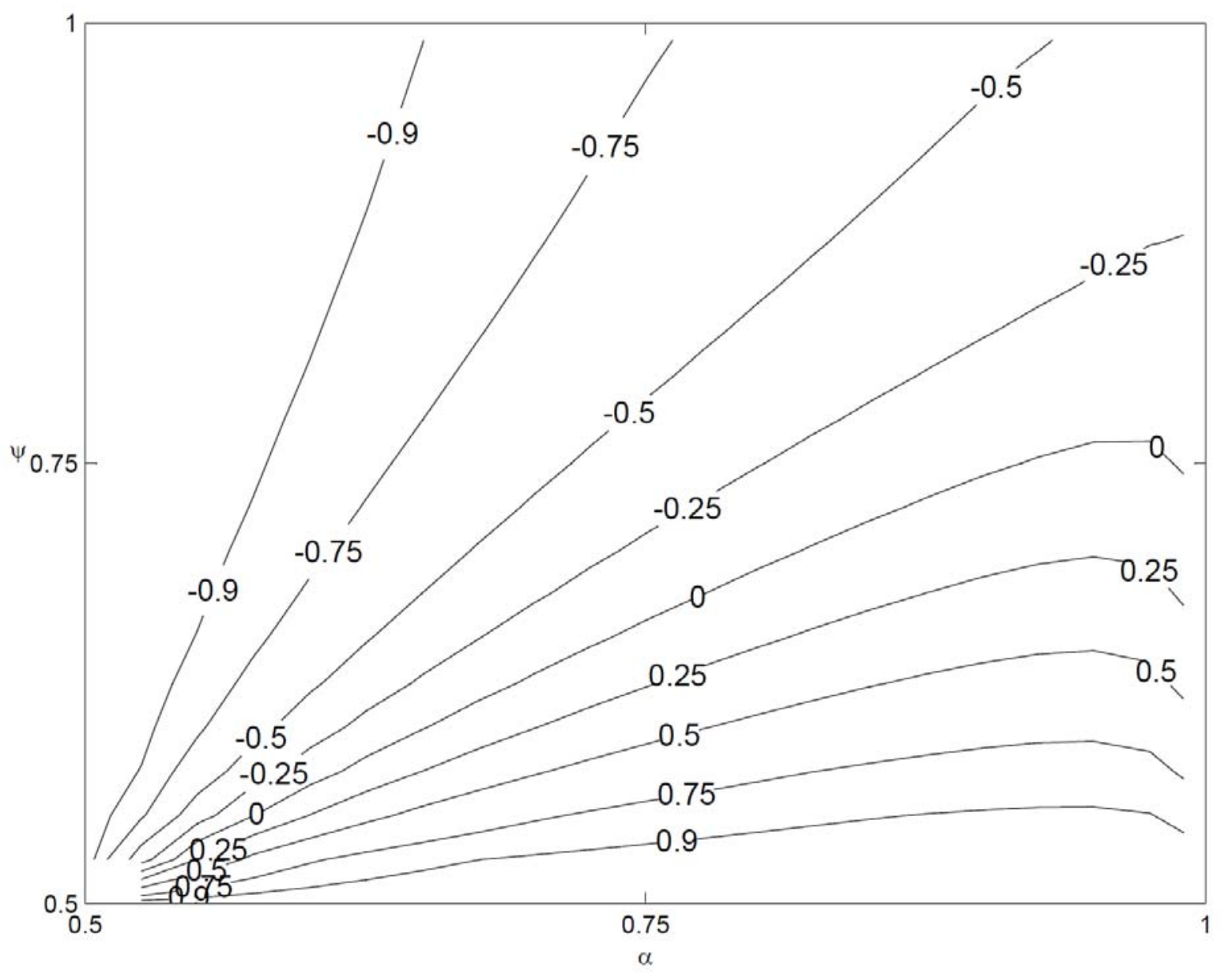

$\alpha$ denotes the size of the larger exporter. The higher $\alpha$ the more heterogeneous are exporters between a large exporter and a small one $\psi$ denotes the size of the larger importer. The higher $\psi$ the more heterogeneous are importers between a large importer and a small one

Parameters are as in the baseline of Figures 8-12, except for $\zeta_{x}=0.5$ instead of $\zeta_{x}=0$. 